\title{
ISCCP Cloud Properties Associated with Standard Cloud Types Identified in Individual Surface Observations
}

\author{
CARole J. HahN \\ Department of Atmospheric Sciences, The University of Arizona, Tucson, Arizona \\ WiLLIAM B. RosSOW \\ NASA Goddard Institute for Space Studies, New York, New York \\ STEPHEN G. WARREN \\ Department of Atmospheric Sciences, University of Washington, Seattle, Washington
}

(Manuscript received 6 December 1999, in final form 10 February 2000)

\begin{abstract}
Individual surface weather observations from land stations and ships are compared with individual cloud retrievals of the International Satellite Cloud Climatology Project (ISCCP), stage C1, for an 8-yr period (198391) to relate cloud optical thicknesses and cloud-top pressures obtained from satellite data to the standard cloud types reported in visual observations from the surface.

Each surface report is matched to the corresponding ISCCP-C1 report for the time of observation for the 280 $\mathrm{km} \times 280 \mathrm{~km}$ grid box containing that observation. Classes of the surface reports are identified in which a particular cloud type was reported present, either alone or in combination with other clouds. For each class, cloud amounts from both surface and $\mathrm{C} 1$ data, base heights from surface data, and the frequency distributions of cloud-top pressure $\left(p_{c}\right)$ and optical thickness $(\tau)$ from $\mathrm{C} 1$ data are averaged over $15^{\circ}$ latitude zones, for land and ocean separately, for 3-month seasons. The frequency distribution of $p_{c}$ and $\tau$ is plotted for each of the surface-defined cloud types occurring both alone and with other clouds.

The average cloud-top pressures within a grid box do not always correspond well with values expected for a reported cloud type, particularly for the higher clouds $\mathrm{Ci}$, Ac, and $\mathrm{Cb}$. In many cases this is because the satellites also detect clouds within the grid box that are outside the field of view of the surface observer. The highest average cloud tops are found for the most extensive cloud type, Ns, averaging $7 \mathrm{~km}$ globally and reaching $9 \mathrm{~km}$ in the ITCZ. Nimbostratus also has the greatest average retrieved optical thickness, $\tau \approx 20$. Cumulonimbus clouds may actually attain far greater heights and depths, but they do not fill the grid box.

The $\tau-p_{c}$ distributions show features that distinguish the high, middle, and low clouds reported by the surface observers. However, the distribution patterns for the individual low cloud types $(\mathrm{Cu}, \mathrm{Sc}, \mathrm{St})$ occurring alone overlap to such an extent that it is not possible to distinguish these cloud types from each other on the basis of $\tau-p_{c}$ values alone. Other cloud types whose $\tau-p_{c}$ distributions are indistinguishable are $\mathrm{Cb}, \mathrm{Ns}$, and thick As. However, the $\tau-p_{c}$ distribution patterns for the different low cloud types are nevertheless distinguishable when all occurrences of a low cloud type are included, indicating that the different low types differ in their probabilities of co-occurrence with middle and high clouds.
\end{abstract}

\section{Introduction}

The International Satellite Cloud Climatology Project (ISCCP), begun in 1983, provides a global climatology of cloud amounts, cloud-top heights, and optical thicknesses inferred from thermal infrared and visible radiances (Rossow and Schiffer 1991). Clouds are also de-

Corresponding author address: Carole J. Hahn, Department of Atmospheric Sciences, PAS Building 81, The University of Arizona, Tucson, AZ 85721.

E-mail: hahn@ncar.ucar.edu scribed in weather reports from the earth's surface, in which visual observations are used to estimate the fractional coverage of the sky by clouds and to identify clouds by morphological type (WMO 1974, 1975, 1987). Separate cloud climatologies have been published using these two fundamentally different types of observational data (Warren et al. 1986, 1988; Rossow et al. 1991, 1993).

Our previous attempts to compare the surface and satellite cloud climatologies (Rossow et al. 1993; Hahn et al. 1995) focused on analysis of total cloud amount, defined by the ISCCP as the fraction of the earth's surface covered by cloud and in the surface climatology 
(a)

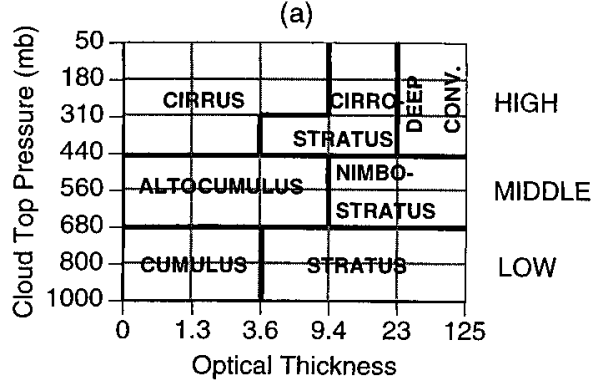

(b)

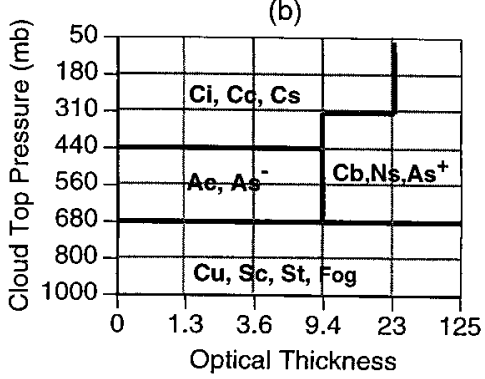

FIG. 1. (a) Correspondence of cloud types as defined in visual surface observations to combinations of optical thickness $\tau$ and cloud-top pressure $p_{c}$ for clouds detected from satellite, as suggested by Rossow et al. (1991). (b) As modified, based on the results of this study. (Here, As - and As + signify thin and thick As.)

as the fraction of the hemispherical sky covered by cloud. At low latitudes and midlatitudes these comparisons showed excellent quantitative agreement in average total cloud amount, but with ISCCP cloud amount tending to be slightly larger over ocean and smaller over land compared to surface observations. Large discrepancies were found in the polar regions, with ISCCP greatly underestimating cloud cover in summer (Schweiger and Key 1992; Fig. 13 of Hahn et al. 1995).

In this paper, rather than comparing only total cloud amounts, we direct attention to the different types of cloud. Comparing cloud types determined from surface observations to those obtained from satellite observations provides an assessment of the importance of the differences in perspective (above vs below), spatial resolution, field of view, and nature of the data (radiometric vs visual). The historical record of surface observations is valuable for climatic change studies because it covers many decades, but there is now increasing reliance on satellite data for cloud information, so it is desirable to be able to relate cloud parameters from satellite retrievals to the traditional cloud types reported in surface observations. The different cloud types are generally indicative of the dynamic and thermodynamic state of the atmosphere (Houze 1993; Lau and Crane 1995, 1997) and also have quite different radiative effects because of their different heights, thicknesses, and shapes (e.g., Chen et al. 2000). In this paper we attempt to relate the radiative properties of clouds, as inferred from satellite data, to the cloud types reported in visual observations from the surface. Rossow et al. (1991) have suggested a correspondence of seven cloud types to satellite-retrieved cloud-top pressure and cloud optical thickness (Fig. 1a). Although the correspondence in Fig. $1 \mathrm{a}$ is reasonable, the results of the present study will indicate that such a correspondence can be established only for the coarser grouping of cloud types shown in Fig. 1b, and explained below.

\section{Data and analysis method}

\section{a. Data sources}

Surface weather observations are usually made eight times daily at land stations (at UTC hours divisible by
3) and four times daily by ships. For this study we used the Edited Cloud Reports Archive (ECRA), a dataset of individual synoptic observations that have undergone some interpretation of their cloud information (Hahn et al. 1996). That dataset covers the years 1982-91; it has recently been expanded to cover the years 1952-95 for ocean and 1971-96 for land (Hahn and Warren 1999). These reports originally came from the National Meteorological Center (NMC, now the National Centers for Environmental Prediction NCEP) for land stations and from the Comprehensive Ocean-Atmosphere Data Set (COADS; Woodruff et al. 1987) for ships. To create the ECRA, the information relating to clouds in the reports from NMC and COADS, including the present weather information, was extracted and put through a series of quality control checks. Reports not meeting certain quality control standards were rejected. Minor correctable inconsistencies within reports were edited for consistency. Cases of "sky obscured" were interpreted by reference to the present weather code as to whether they indicated fog, rain, snow, or thunderstorm. Special coding was added to indicate probable nimbostratus clouds, which are not specifically coded for in the standard synoptic code. This "edited cloud report" also includes the amounts, either inferred or directly reported, of low, middle and high clouds, both overlapped and nonoverlapped, using the random overlap assumption but qualified based on cooccurrence statistics (Warren et al. 1985, 1986, 1988). The relative lunar illuminance and the solar zenith angle are also given to aid in evaluating the reliability of cloud observations at night (Hahn et al. 1995).

Data from the ECRA for the 8 yr July 1983-June 1991 were used in this study for comparison to ISCCP data of stage C1 (Rossow et al. 1991) for the same period of record. ${ }^{1}$ The radiance data used by ISCCP

\footnotetext{
${ }^{1}$ Reprocessing is now under way to form the ISCCP D-series dataset (Rossow et al. 1996; Rossow and Schiffer 1999), which will supersede the C-series data used in this and previous studies. The Dseries analysis uses data from an additional satellite channel at 3.7$\mu \mathrm{m}$ wavelength and uses an ice-cloud model for cold clouds.
} 
TABLE 1. Symbols used, and definitions of cloud and weather types using the synoptic code (Hahn et al. 1996). Synoptic code symbols are total cloud cover $(N)$, low cloud type $\left(C_{L}\right)$, middle cloud type $\left(C_{M}\right)$, high cloud type $\left(C_{H}\right)$, and present weather (ww). The symbol "/" means that the variable is unreported; e.g., upper clouds are normally unreported when the low cloud is overcast.

\begin{tabular}{|c|c|c|}
\hline Abbreviation & Meaning & Synoptic code values \\
\hline TCA & Total cloud amount & $\begin{array}{c}N=1-8 \text { for } 1 / 8-8 / 8 \text { sky cover } \\
N=9 \text { if sky is obscured }\end{array}$ \\
\hline Clear & Completely clear sky & $N=0$ \\
\hline \multicolumn{3}{|l|}{ High clouds: } \\
\hline $\mathrm{Ci} / \mathrm{Cs} / \mathrm{Cc}$ & $\begin{array}{l}\text { Cirrus, cirrocumulus } \\
\text { Cirrostratus } \\
\text { Dense cirrus }\end{array}$ & $\begin{array}{l}C_{H}=1,4,9 \\
C_{H}=5,6,7,8 \\
C_{H}=2,3\end{array}$ \\
\hline \multicolumn{3}{|c|}{ Middle clouds: } \\
\hline Ns & Nimbostratus & $\begin{array}{l}C_{M}=2,7, \text { or } N=9, \text { with ww }=\mathrm{DRS} \\
C_{M}=/ \text { with ww }=\mathrm{DRS} \text { and } C_{L}=0,7 \\
C_{M}=/ \text { with ww }=\mathrm{RS} \text { and } C_{L}=4-8\end{array}$ \\
\hline Ac & Altocumulus & $\begin{array}{c}C_{M}=3,4,5,6,8,9 \\
C_{M}=7 \text { if not DRS }\end{array}$ \\
\hline As & Altostratus & $C_{M}=1 ; 2$ if not DRS \\
\hline \multicolumn{3}{|l|}{ Low clouds: } \\
\hline $\mathrm{Cu}$ & Cumulus & $C_{L}=1,2$ \\
\hline $\mathrm{Cb}$ & Cumulonimbus & $C_{L}=3,9$, or $N=9$ with $\mathrm{ww}=\mathrm{Ts}$ \\
\hline $\mathrm{Sc}$ & Stratocumulus & $C_{L}=4,5,8$ \\
\hline St & Stratus & $C_{L}=6,7$ \\
\hline Fog & Sky obscured by fog & $\begin{array}{l}C_{L}=/ \text { with } N=9 \text { and } \\
\text { ww }=10-12,40-49\end{array}$ \\
\hline \multicolumn{3}{|l|}{ Precipitation } \\
\hline $\mathrm{D}$ & Drizzle & $\mathrm{ww}=50-59$ \\
\hline $\mathrm{R}$ & Rain & $\mathrm{ww}=60-69$ \\
\hline $\mathrm{S}$ & Snow & $\mathrm{ww}=70-75,77,79$ \\
\hline Ts & Thunderstorm, shower & $\mathrm{ww}=80-99$ \\
\hline
\end{tabular}

have a spatial resolution (pixel size) of 4-7 km. Each pixel is classified as to whether cloud is present or absent; if cloud is present its cloud-top pressure, $p_{c}$, and optical thickness, $\tau$, are inferred from the thermal infrared and visible radiances, respectively, during daytime. At night only $p_{c}$ is retrieved. For each month, the ISCCP-C1 data provide, for each grid box of size 280 $\mathrm{km} \times 280 \mathrm{~km}$ and for each 3 -h period during the daytime, the fraction of observations falling into each of five $\Delta \tau$ ranges and seven $\Delta p_{c}$ ranges, a total of 35 bins in a two-dimensional $\tau-p_{c}$ space (Fig. 1a). The fraction of pixels classified as containing cloud represents the total cloud amount for the grid box (and similarly within each of the $35 \tau-p_{c}$ bins).

\section{b. Analysis procedure}

For this study we matched each surface observation to the ISCCP-C1 report for the same date and time for the $280-\mathrm{km}$ grid box containing the surface observation. If more than one surface observation was made at the same time in the same grid box, each of the surface observations was compared separately to the same ISCCP report. To facilitate the interpretation, nighttime observations were excluded from the analysis (because ISCCP cannot infer $\tau$ at night) and many coastal observations were also excluded (because the cloud amounts and types often change abruptly at coastlines, so that agreement of a single surface observation with ISCCP's grid-box average cannot be expected). Specifically, observations were used only if the solar elevation exceeded $11.5^{\circ}$ (so that ISCCP was able to use data from both visible and thermal infrared channels) and only if the observations fell within ISCCP grid boxes classified either as land (land fraction $\geq 0.65$ ) or as ocean (ocean fraction $\geq 0.65$ ).

Surface synoptic observations contain the following information about clouds: total cloud cover $(N)$, low or middle cloud amount $\left(N_{h}\right)$, low cloud type $\left(C_{L}\right)$, middle cloud type $\left(C_{M}\right)$, high cloud type $\left(C_{H}\right)$, and present weather (ww). Reporting in the synoptic code requires a choice of one of nine code values for $C_{L}$, and similarly for $C_{M}$ and $C_{H}$. Hahn et al. (1996) grouped these 27 code values into 11 cloud types as specified in Table 1. Abbreviations for the cloud types are also defined in Table 1.

A few comments may help to explain the groupings in Table 1 . The low cloud type $C_{L}=8$ means cumulus under stratocumulus; we classify this type as Sc because the view from above should be of Sc. Although the synoptic code distinguishes thin cirrus $\left(C_{H}=1,4\right)$ from thick cirrus $\left(C_{H}=2,3\right.$, originating from $\left.\mathrm{Cb}\right)$, the code values for "cirrostratus" $\left(C_{H}=5,6,7,8\right)$ can all be applied to uniform high clouds of any thickness, precluding a correspondence of surface-defined cloud types to optical depth categories of cirriform clouds. We there- 
TABLE 2. Number of surface observations (in thousands) analyzed for 8 yr of the seasons DJF and JJA (1983-84 to 1990-91), for the two zones whose results are discussed in the text. Alone means the observations in which the specified type was the only type of cloud in the sky; all means all observations of the specified type, including observations in which other cloud types were also present.

\begin{tabular}{|c|c|c|c|c|c|c|c|c|c|}
\hline \multirow{3}{*}{$\begin{array}{l}\text { Total DJF } \\
\text { Total JJA }\end{array}$} & & \multicolumn{4}{|c|}{$30^{\circ}-45^{\circ} \mathrm{N}$} & \multicolumn{4}{|c|}{$0^{\circ}-15^{\circ} \mathrm{N}$} \\
\hline & & \multicolumn{2}{|c|}{$\begin{array}{l}\text { Land } \\
1209 \\
1945\end{array}$} & \multicolumn{2}{|c|}{$\begin{array}{c}\text { Ocean } \\
282 \\
403\end{array}$} & \multicolumn{2}{|c|}{$\begin{array}{c}\text { Land } \\
318 \\
335\end{array}$} & \multicolumn{2}{|c|}{$\begin{array}{c}\text { Ocean } \\
110 \\
119\end{array}$} \\
\hline & & Alone & All & Alone & All & Alone & All & Alone & All \\
\hline \multirow[t]{2}{*}{$\mathrm{Ci} / \mathrm{Cs} / \mathrm{Cc}$} & DJF & 205 & 384 & 5 & 57 & 81 & 161 & 3 & 36 \\
\hline & JJA & 151 & 560 & 14 & 85 & 16 & 154 & 2 & 45 \\
\hline \multirow[t]{2}{*}{$\mathrm{Ac} / \mathrm{As}$} & DJF & 35 & 300 & 4 & 108 & 5 & 84 & 1 & 50 \\
\hline & JJA & 61 & 501 & 7 & 129 & 4 & 178 & 1 & 64 \\
\hline \multirow[t]{2}{*}{ Ns } & DJF & - & 84 & - & 17 & - & 3 & - & 2 \\
\hline & JJA & - & 77 & - & 12 & - & 8 & - & 4 \\
\hline \multirow[t]{2}{*}{$\mathrm{Cb}$} & DJF & 4 & 39 & 3 & 24 & 2 & 18 & 2 & 14 \\
\hline & JJA & 26 & 171 & 3 & 22 & 4 & 56 & 1 & 20 \\
\hline \multirow[t]{2}{*}{$\mathrm{Cu}$} & DJF & 57 & 174 & 22 & 99 & 31 & 93 & 17 & 58 \\
\hline & JJA & 271 & 625 & 32 & 133 & 23 & 120 & 10 & 57 \\
\hline \multirow[t]{2}{*}{$\mathrm{Sc}$} & DJF & 44 & 244 & 9 & 83 & 9 & 51 & 2 & 19 \\
\hline & JJA & 57 & 286 & 9 & 95 & 7 & 97 & 2 & 22 \\
\hline \multirow[t]{2}{*}{$\mathrm{St}$} & DJF & 5 & 86 & 1 & 48 & 1 & 8 & 0.3 & 8 \\
\hline & JJA & 6 & 86 & 2 & 54 & 1 & 16 & $<1$ & 11 \\
\hline \multirow[t]{2}{*}{ Fog } & DJF & - & 16 & - & 2 & - & 0.2 & - & 0.2 \\
\hline & JJA & - & 13 & - & 29 & - & 0.3 & - & 0.1 \\
\hline
\end{tabular}

fore group all the surface-observed cirriform clouds together and use the abbreviation " $\mathrm{Ci}$ " to mean $\mathrm{Ci} / \mathrm{Cc} /$ Cs. We also group altostratus (which does not appear in Fig. 1a) together with altocumulus; we use the abbreviation "Ac" to refer to this Ac/As group, since the altocumulus subtypes make up the largest fraction of the group. Nevertheless, in some discussions it will be useful to distinguish Ac, thin $\mathrm{As}\left(C_{M}=1\right)$, and thick As $\left(C_{M}=2\right)$ (Table 1$)$.

Translating a visual observation of the sky into the synoptic reporting code often results in a loss of information, which can hinder the comparison with satellite observations. For example, if several low cloud types are present simultaneously they may all be seen by satellite but the surface synoptic code permits only one of them to be reported, according to rules of priority specified by WMO (1974).

We classified the observations by three-month season (DJF, MAM, JJA, SON, where, for example, DJF is December-January-February), grouped into $15^{\circ}$ latitude zones (but $30^{\circ}$ zones at the poles, $60^{\circ}-90^{\circ}$ ), keeping land and ocean separate. The oceanic observations were all made by ships; island and coastal stations do not contribute to our oceanic analyses. We further classified the reports according to whether they contained a particular cloud type, and whether that cloud type was reported to be alone or together with other clouds in the ground observer's field of view. We considered a lower cloud type to be alone if it was the only cloud type reported present and if it covered no more than $75 \%$ of the sky so that a higher cloud had a good chance of being seen if it was present. This criterion was based on analyses of Warren et al. (1988, their Fig. 6).

In the analysis below we select ISCCP-C1 reports made at the same time as a surface observation of a specified cloud type (e.g., cirrus). A subset of these selected ISCCP reports is then identified in which the surface observation contained only the one specified cloud type (the "alone" cases). The full set of selected ISCCP reports coincident with a surface observation containing the specified cloud type, irrespective of whether other clouds were also present, are called the "all" cases. The "alone" cases were meant to represent pure scenes for a particular cloud type, whereas the "all" cases were meant to include all scenes in which that cloud type occurs. The "alone" cases are used to evaluate the correspondence of cloud-type definitions used by ISCCP to the cloud-type definitions used in surface observations.

Analyses were performed for all seasons and all zones. We will show, for each cloud type for DJF, the latitudinal variations of average values of ISCCP total cloud amount (TCA), cloud-top pressure $\left(p_{c}\right)$, and optical thickness $(\tau)$. For the two-dimensional $\tau-p_{c}$ distributions contingent on each surface-reported type we show results from DJF and JJA only for the latitude zone $30^{\circ}-45^{\circ} \mathrm{N}$. The number of surface observations (in thousands) used in each analysis is given in Table 2 for the zones $0^{\circ}-15^{\circ} \mathrm{N}$ and $30^{\circ}-45^{\circ} \mathrm{N}$ for DJF and JJA. Some cloud types are rarely observed alone, particularly over the ocean. The types most often seen alone are cirrus over land and cumulus over both land and ocean. No entries are given in Table 2 for nimbostratus alone or fog alone. This is because nimbostratus almost always appears overcast to the surface observer, so we usually cannot exclude the possibility of a co-occurring high cloud. And our "fog" category consists of the synoptic code values meaning "sky obscured due to fog," so we 

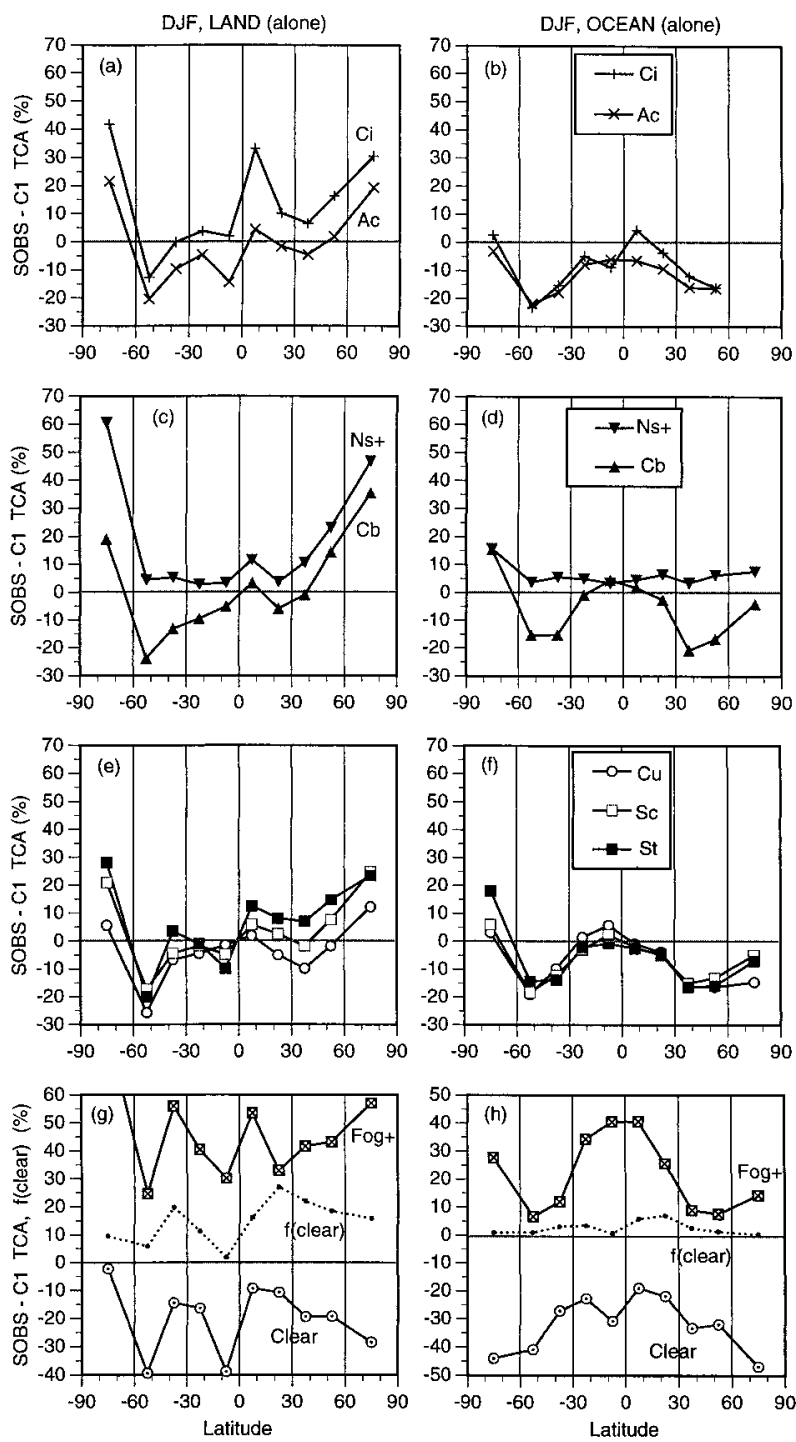

FIG. 2. Percent difference between TCA reported in SOBS and in ISCCP-C1 data, for scenes in which a specified SOBS cloud type was reported alone, as a function of latitude (negative latitudes mean Southern Hemisphere). The symbols Ns + and Fog + indicate that all observations containing these types were used. Also shown in $(\mathrm{g})$ and $(\mathrm{h})$ is the TCA difference for surface reports of clear sky, together with the frequency of occurrence of clear sky, f(clear). Left-hand panels are for land; right-hand panels for ocean; all are for the season DJF.

cannot exclude the possibility of other clouds above the fog.

\section{Latitudinal variations of average cloud amount, height, and optical thickness}

\section{a. Average cloud amount}

Figure 2 compares surface-observed (SOBS) TCA to the ISCCP-C1 TCA for observations in which particular cloud types were reported alone in DJF. Because cases of Ns alone and fog alone are not available, the all cases of Ns and fog are shown, labeled "Ns+" and "Fog +." What is shown in Fig. 2 is just the average difference in TCA; the root-mean-square difference of individual comparisons of TCA is much larger, typically $25 \%$ [cf. discussion in Rossow et al. (1993)].

There is a general tendency for SOBS TCA to be smaller than C1 TCA over the ocean. The reverse is true over land, where SOBS TCA exceeds C1 TCA, particularly in winter (i.e., in the Northern Hemisphere in Fig. 2, which is for DJF). These tendencies were previously noted by Rossow et al. (1993); they are likely due to higher thresholds being required for satellites to detect clouds over land, because the horizontal variability of surface albedo and surface temperature is greater over land than over ocean.

The large positive differences for fog are due to the fact that fog is often localized. The surface observer sees only the fog while the satellite also sees nonfoggy regions in the same grid box. The TCA differences are small in midlatitude oceans where the fog may be more extensive. A similar situation may account for the uniformly positive TCA differences seen for Ns, but those differences are rather small because Ns typically covers a large region. This issue is discussed further in section 5 , where we analyze cases of multiple simultaneous surface observations in a $\mathrm{C} 1$ grid box.

We also examined the ISCCP observations corresponding to surface reports of completely clear sky. The ISCCP cloud amount in these grid boxes was not zero but instead averaged 20\%-30\% (Figs. 2g,h). The explanation for this discrepancy is that the ground observer's field of view is smaller than a $280-\mathrm{km}$ grid box, so that when "clear sky" is reported clouds may still exist elsewhere in the grid box, particularly at the low cloud level, for which the ground observer's field of view is smaller (Rossow et al. 1993). The probability of an entire grid box being clear should be greater at latitudes where the frequency of surface reports of clear sky is greater. This is indeed seen in Figs. $2 \mathrm{~g}, \mathrm{~h}$ where the clear-sky frequency is also plotted and shown to be larger at latitudes where the ISCCP cloud amount at times of clear reports is less.

Figure 3 shows the difference in TCA for all observations of a particular cloud type in DJF. There is generally better agreement between $\mathrm{C} 1$ and SOBS total cloud amounts here, suggesting that the alone cases in Fig. 2 had less total cloud amount than the average for their grid boxes because they were selected to be alone. This effect could explain the cases of large negative differences at midlatitudes seen in Fig. 2. The righthand (ocean) panels of Fig. 3 show good agreement of C1 TCA with SOBS TCA over the low-latitude ocean $\left(30^{\circ} \mathrm{N}-30^{\circ} \mathrm{S}\right)$ but show $\mathrm{C} 1 \mathrm{TCA}$ to exceed SOBS TCA in midlatitudes for all types except Ns and St. This may be an effect of the viewing angle of geostationary satellites (Rossow et al. 1993), which would be insignificant for horizontally uniform clouds like Ns and St. 

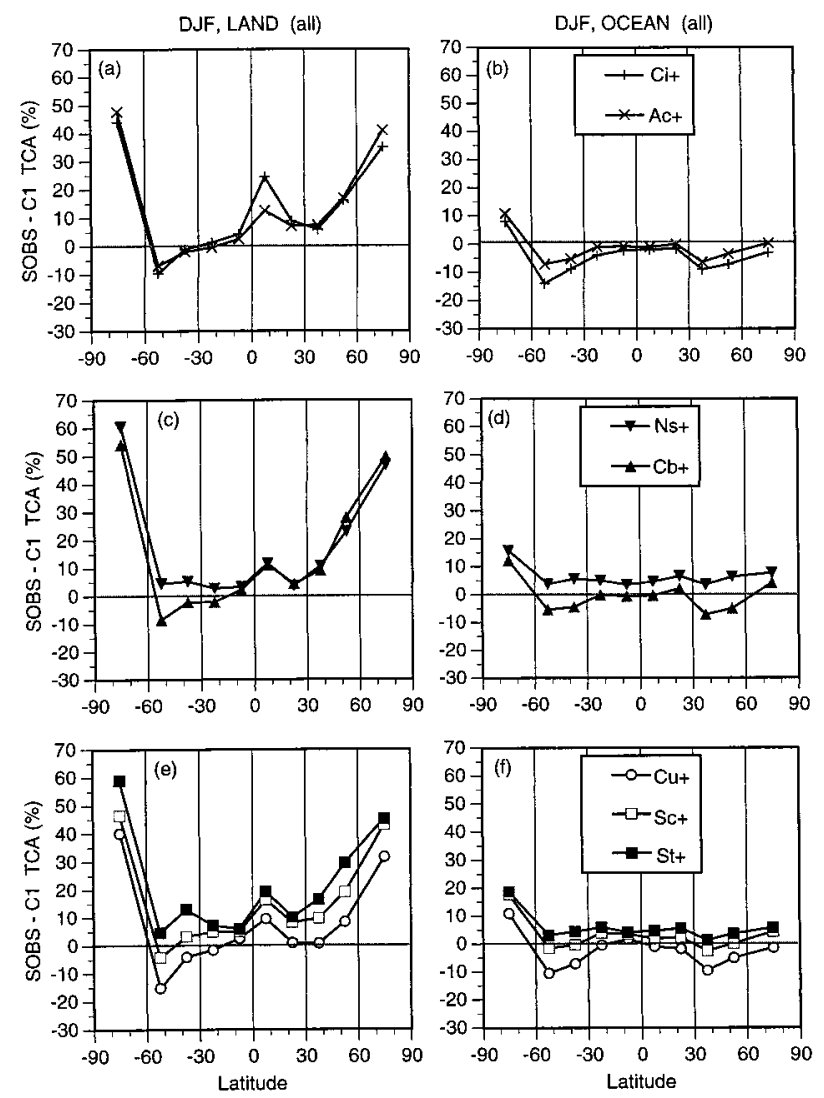

FIG. 3. Same as Fig. 2, but for all scenes including a report of a particular cloud type, irrespective of whether other clouds are also present.

Over Northern Hemisphere midlatitude land in DJF (Figs. 3a,c,e) SOBS TCA exceeds C1 TCA; this is probably due in part to ISCCP's difficulty in detecting clouds over snow.

\section{b. Average cloud heights}

The area-mean cloud-top pressures for all ISCCPC1 reports coincident with surface observations of a particular cloud type in a $15^{\circ}$ latitude zone were averaged. (We define a "coincident" ISCCP report as the ISCCP report for a $280-\mathrm{km}$ grid box for a 3 -h period during which at least one surface observation was made.) The average pressure obtained was converted into an approximate cloud-top height above sea level using a scale height of $8 \mathrm{~km}$. Only the pressures of pixels diagnosed as cloudy by ISCCP were averaged. The cloud heights for the different types alone, in DJF, are shown in Fig. 4.

In Figs. 4e,f, the cloud-top heights associated with the low clouds $\mathrm{Cu}, \mathrm{St}$, and $\mathrm{Sc}$ alone are generally 3-4 $\mathrm{km}$ above sea level over land and $2-3 \mathrm{~km}$ over the ocean. For comparison, the base heights of the low clouds above ground level, as estimated by the surface observers, are shown in Figs. 4g and 4h. Over the ocean,
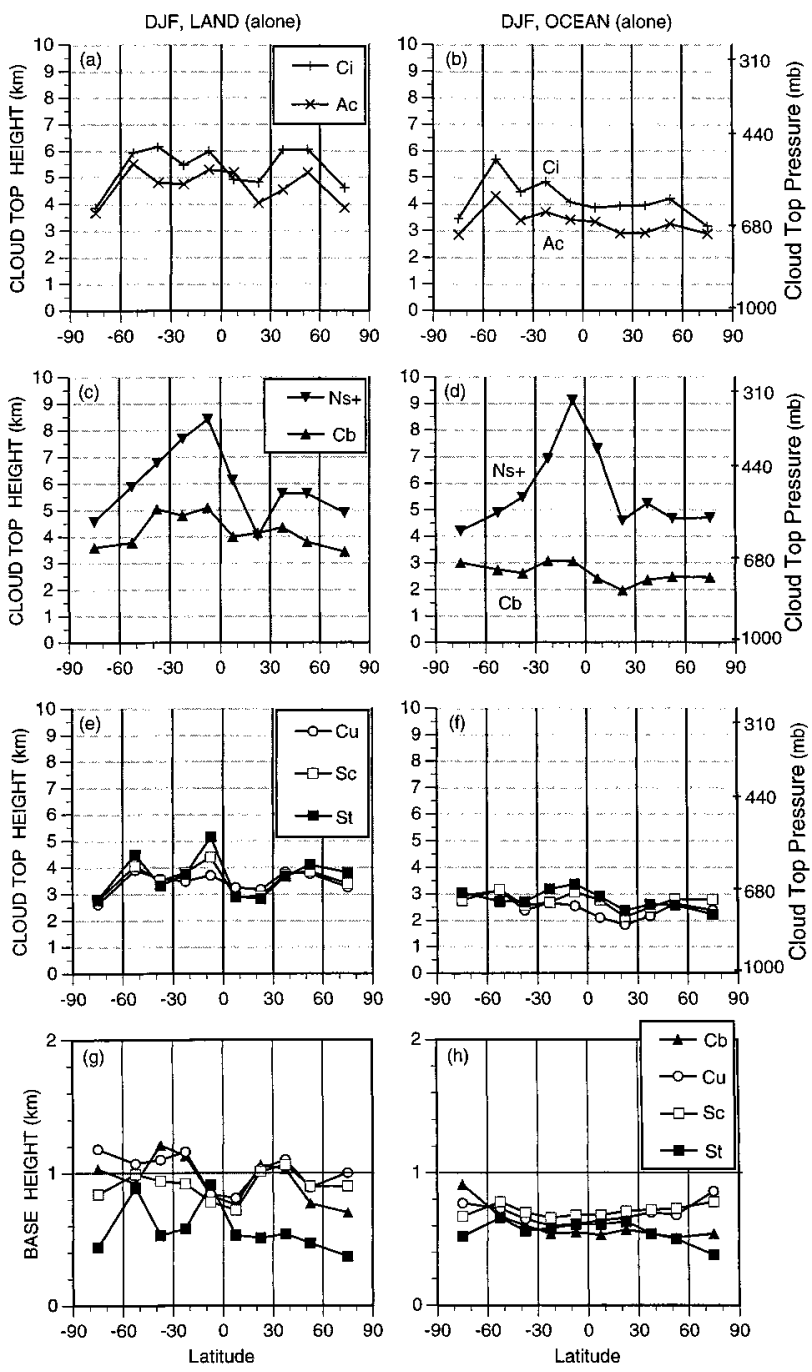

FIG. 4. Cloud-top height above sea level corresponding to the average cloud-top pressure in $\mathrm{C} 1$ retrievals for grid boxes containing surface observations of the specified cloud type occurring alone (except for "Ns+," in which all cases of Ns contribute). (g) and (h) The average cloud-base heights above ground level as given in the surface reports.

the cloud bases for these types at low latitudes and midlatitudes are consistently between 0.5 and $0.8 \mathrm{~km}$ above the surface. Over land, the bases of $\mathrm{Cb}, \mathrm{Cu}$, and Sc are somewhat higher, particularly in the subtropics. Thus, the 1-km greater cloud-top heights over land can be accounted for by the height of the land surface above mean sea level (average $0.5 \mathrm{~km}$ ) and the fact that cloud bases are on average higher (above ground level) over land than over ocean, by about $0.4 \mathrm{~km}$ (Warren et al. 1986, 1988). The difference between top height and base height implies a mean cloud layer thickness of 1-2 km, consistent with inferences from rawinsonde humidity profiles (Table 1 of Wang et al. 2000). However, the top heights obtained for the low clouds may be biased high 
by the presence of higher clouds not seen by the surface observer (see discussion in Wang et al. 1999).

The cloud-top heights for the cases of $\mathrm{Cb}$ and $\mathrm{Ci}$ alone are only 2-3 and 4-5 km respectively over ocean and $1 \mathrm{~km}$ higher over land; that is, far below the tropopause. Low diagnosed heights for a high cloud can result when the cloud does not fill a grid box and the satellite also detects lower clouds in parts of the grid box outside the field of view of the surface observer. Table 2 indicates that, except for $\mathrm{Ci}$ over land, these clouds ( $\mathrm{Cb}, \mathrm{Ac}, \mathrm{Ci})$ rarely occur alone. Furthermore, in the case of $\mathrm{Ci}$, even if the entire grid box is covered with high clouds, the clouds may be insufficiently thick to be opaque in the thermal infrared, so they can be misassigned to a lower height. In the case of $\mathrm{Cb}$, because of its shape, parts of the cloud itself are low, so that the low height assignments are due not only to the presence of other low clouds but also (in an off-nadir view) to low portions of the $\mathrm{Cb}$ cloud. Also, oceanic $\mathrm{Cb}$ often do not extend to the tropopause (Johnson et al. 1999). Moreover, Cb generally cover only small areas, but within a larger region they usually appear in a complex mix of cloud types at different stages of their life cycles.

Nimbostratus as reported by surface observers is most common in the midlatitudes and high latitudes (Warren et al. 1986, 1988). It is much less common over most of the Tropics and subtropics where precipitation is mostly the result of convection and therefore occurs with $\mathrm{Cb}$ clouds. However, in each season Ns is reported with a frequency of several percent throughout the Tropics, and there is a small peak in its latitudinal distribution at the location of the intertropical convergence zone (ITCZ) both on land and ocean [Fig. 7 of Warren et al. (1986); Fig. 11 of Warren et al. (1988)]. Surface observers are instructed to report clouds as $\mathrm{Cb}$ if the precipitation is showery, or if accompanied by thunder, lightning, or hail, and as Ns if the cloud is of great horizontal extent and evidence of convective activity is absent (WMO 1974, 1975, 1987). This stratiform precipitation in the Tropics occurs in the decaying phase of thunderstorms (Houze 1997). Tropical nimbostratus was also recognized by Ramage (1971, p. 24, chap. 4).

Nimbostratus is the only cloud for which the average cloud-top height in a $280-\mathrm{km}$ ISCCP grid box exceeds $6 \mathrm{~km}$, reaching $9 \mathrm{~km}$ in the ITCZ. The large peak seen for $\mathrm{Ns}$ in the zone $0^{\circ}-15^{\circ} \mathrm{S}$ in Fig. $4 \mathrm{~d}$ (as well as the smaller peaks seen for the low cloud types) shifts to $0^{\circ}-$ $15^{\circ} \mathrm{N}$ in JJA. The diagnosed heights for Ns are thus higher than those for $\mathrm{Ci}$, contrary to expectation. This is due in part to the fact that $\mathrm{Ci}$ is often optically thin and occurs together with low-level clouds (Warren et al. 1985), leading to misassignment by the satellite in $\mathrm{C} 1$ data due to the use of a liquid-droplet phase function (Minnis et al. 1993; Jin and Rossow 1997). Another reason for low heights of $\mathrm{Ci}$ is misassignment of the cloud type by the surface observer, who sometimes cannot distinguish As from Cs.

Allowing all cases of a cloud type to contribute to the averages (not shown) does not change the average cloud-top heights of $\mathrm{Ci} / \mathrm{Cs} / \mathrm{Cc}$ and As/Ac. The averages are higher for the "all" cases of $\mathrm{Cu}, \mathrm{Cb}, \mathrm{Sc}$, and St than for these types alone, as expected, since in many of the "all" cases middle and high clouds are present above the low clouds.

The above discussion does not imply errors in retrieving cloud properties from space since we have compared area-averaged cloud properties from ISCCP with point identifications of cloud type. The ISCCP datasets also report the frequency distribution of individual clouds (identified at the pixel level), which we will discuss in section 4 . We will examine this issue further in section 5 by considering examples where several surface observations were made simultaneously in one grid box.

\section{c. Average cloud optical thicknesses}

Area-mean cloud optical thickness $\tau$, shown in Fig. 5 , is inferred from reflected sunlight in the visible channel. Except for clouds in the polar regions, where inferred optical thicknesses are probably excessive because they were treated as liquid water clouds (Rossow and Schiffer 1999), the largest values of $\tau$ are found for Ns $(\tau \approx 20)$. Over the ocean, all other cloud types (when alone) are associated with satellite-derived optical thicknesses of 3-5. Even for $\mathrm{Cb}$ the thicknesses are not significantly greater than those for $\mathrm{Ci}$. However, these optical thickness values are area averages over a mixture of cloud types as discussed above. Moreover, the reported area-averaged $\tau$ is that which would give the area-averaged albedo $\alpha$ for a plane-parallel cloud (Rossow et al. 1991), so it is less than the linear average of $\tau$ for the area, because the function $\alpha(\tau)$ is concave downward. For example, optical thicknesses of 3-5 are inferred for oceanic Sc, but linearly averaged values would be about three times larger, and comparable to the values of 15-30 reported in aircraft experiments [e.g., Table 3 of Twohy et al. (1989)]. The horizontal variation of $\tau$ is even greater for the convective clouds $\mathrm{Cu}$ and $\mathrm{Cb}$ than for Sc. Analyses of high-resolution Landsat images show that $\mathrm{Cu}$ and $\mathrm{Cb}$ cloud fields are, in fact, dominated by clouds with small optical thicknesses (Wielicki and Parker 1992; Chambers et al. 1997).

Figure 5f shows that $\tau(\mathrm{St})>\tau(\mathrm{Sc})>\tau(\mathrm{Cu})$, as expected. This result was also found by Pincus et al. (1999, their Fig. 5a) for clouds in the eastern Pacific at $20^{\circ}-$ $50^{\circ} \mathrm{N}$, but the effective optical depths they found were about $50 \%$ greater than those reported by ISCCP.

Clouds over land (left-hand side of Fig. 5) have larger optical thicknesses than do clouds of the same type over the ocean (right-hand side of Fig. 5); this is probably due to a smaller average drop size rather than to a greater liquid water path. In fact, using the average drop sizes found by Han et al. (1994) and the linearly averaged optical thicknesses, we find that the average liquid water path is about the same over land as over ocean. For most 

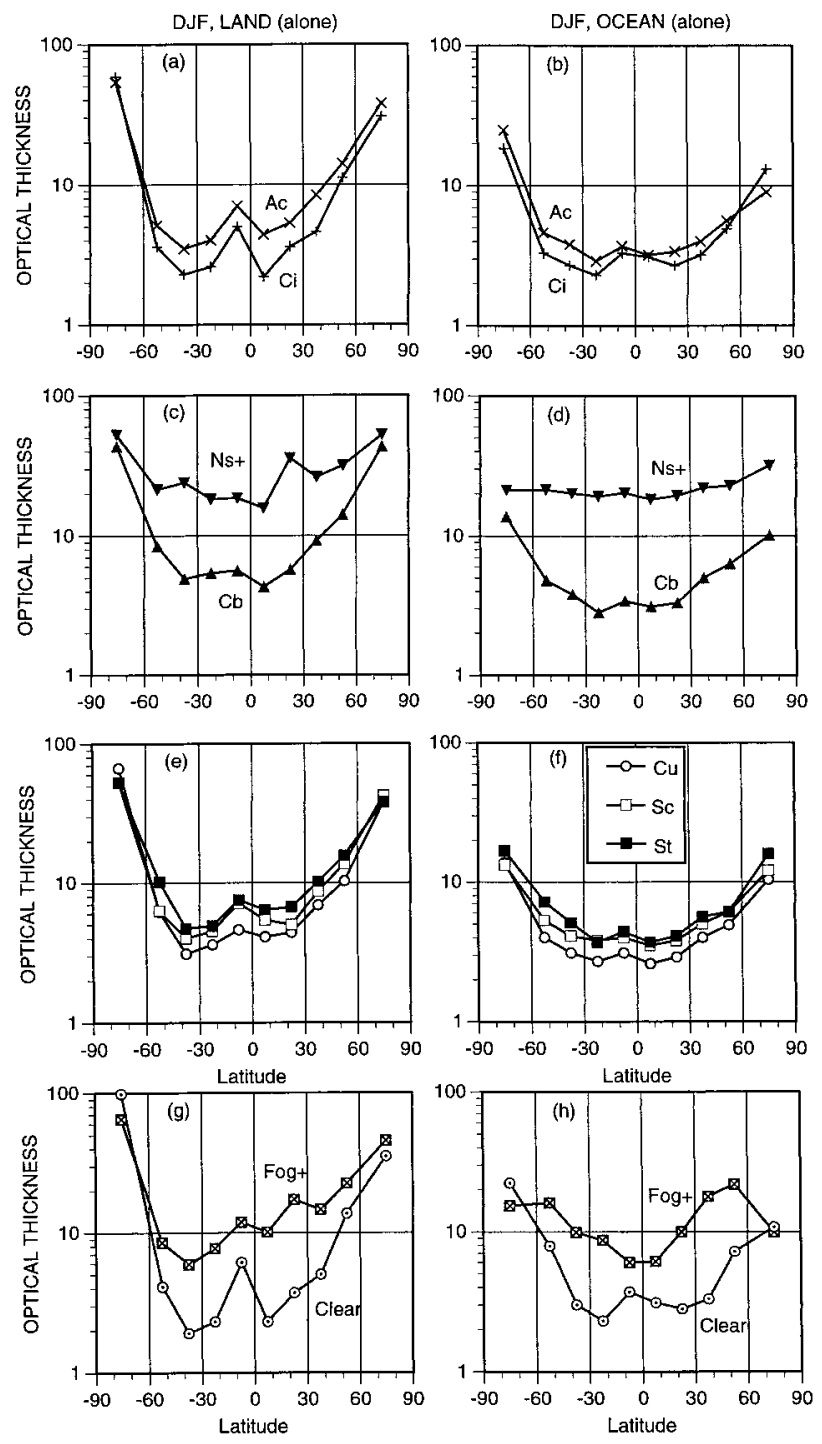

FIG. 5. ISCCP-retrieved average cloud optical thickness for grid boxes containing surface observations of the specified cloud type occurring alone (except for "Ns+," in which all cases of Ns contribute).

cloud types, the inferred optical thickness is greater by a factor of 2 for the "all" cases than for the "alone" cases (Table 3); this is because the optical thickness reported by ISCCP-C1 is the sum of the optical thicknesses of all superimposed clouds.

Table 3 summarizes the average values obtained, for each surface-defined cloud type, of total cloud amount, cloud-base height, cloud-top height, and optical thickness. It shows, for example, that a surface report of Ns is usually representative of a $2.5^{\circ}$ box, as $93 \%$ of the pixels are diagnosed as cloudy, whereas a surface report of clear sky is often not, as only $70 \%-80 \%$ of the pixels are diagnosed as clear. It is also interesting to note that when a low cloud occurs alone, its base height tends to be slightly higher than when it occurs together with higher clouds. This result is also found by Wang et al. (2000).

\section{Frequency distributions of optical thickness and cloud-top pressure for each cloud type}

In each $280-\mathrm{km}$ grid box in a particular $3-\mathrm{h}$ period on a particular day, on average about 45 pixels are diagnosed by ISCCP as being cloudy and are assigned values of $\tau$ and $p_{c}$. In the figures discussed so far (Figs. $2-5)$ the area-averaged values of $\tau$ and $p_{c}$ were presented. We now examine, in Figs. 6-9, two-dimensional frequency distributions of $\left(\tau, p_{c}\right)$ to determine the extent to which surface-defined cloud types can be identified uniquely from satellite radiance data, as suggested by Fig. 1a. Since the traditionally defined cloud types do differ in their heights and thicknesses as well as in their shapes, such a classification is reasonable, identifying, for example, cirrus as a thin high cloud, altocumulus as a thin middle cloud, and deep convective clouds as both high and thick. The cloud boundary lines of Fig. 1a are overlain in Figs. 6 and 7 (the alone cases) to examine how well the observed cloud types fit this scheme. The revised boundaries of Fig. 1b are incorporated into Figs. 8 and 9 (the "all" cases) to show the improved fit of the new scheme.

Frequency distributions such as those shown in Figs. 6-9 were obtained by averaging all individual distributions, separately for each of the four seasons and each of 10 latitude zones. The results displayed here are mostly restricted to the latitude zone $30^{\circ}-45^{\circ}$ in the season DJF, with a few additional examples from JJA, but these examples suffice to illustrate our conclusions, which are also supported by the frequency distributions from other zones and seasons not shown.

The distributions of $\left(\tau, p_{c}\right)$ values are given in the $\mathrm{C} 1$ dataset as counts in each of 35 bins (seven ranges of $p_{c}$ and five ranges of $\tau$ whose boundaries are indicated by tick marks in the figures). For Figs. 6-9 these counts are normalized to a total of $100 \%$ and the array of 35 points (each with the units "percent per $\tau-p_{c}$ bin") is contoured.

\section{a. Low cloud types alone}

Figure 6 shows the $\tau-p_{c}$ distributions associated with surface reports of low clouds occurring alone in DJF in the zone $30^{\circ}-45^{\circ} \mathrm{N}$. (For $\mathrm{Cb}$ the distribution is shown for JJA rather than DJF, because $\mathrm{Cb}$ is more common in summer.) The three types $\mathrm{Cu}, \mathrm{Sc}$, and $\mathrm{St}$ all show the same general pattern, with predominantly low cloud tops and low-to-moderate optical thicknesses. The pattern for these three types over land (left-hand side of Fig. 6) differs from that over ocean in that over land there is an additional contribution from somewhat higher and thicker clouds. This difference can be explained, in part, by the higher land surface and higher cloudbase heights, leading to higher cloud tops over land and 
TABLE 3. Mean values for the "all" and "alone" cases of each surface-defined cloud type, and of total cloud amount (TCA), cloud-base height $\left(z_{B}\right)$, cloud-top height $\left(z_{T}\right)$, and optical thickness $(\tau)$. These averages are over the latitude range $45^{\circ} \mathrm{N}-45^{\circ} \mathrm{S}($ area weighted) and over all four seasons, but separate for land and ocean.

\begin{tabular}{|c|c|c|c|c|c|c|c|c|c|c|}
\hline & \multicolumn{2}{|c|}{ TCA (C1) $(\%)$} & \multicolumn{2}{|c|}{ TCA (SOBS) $(\%)$} & \multicolumn{2}{|c|}{$z_{B}(\mathrm{~m})$} & \multicolumn{2}{|c|}{$z_{T}(\mathrm{~m})$} & \multicolumn{2}{|c|}{$\tau$} \\
\hline & Land & Ocean & Land & Ocean & Land & Ocean & Land & Ocean & Land & Ocean \\
\hline \multicolumn{11}{|l|}{ All } \\
\hline $\mathrm{Ci}$ & 55 & 65 & 62 & 61 & - & - & 5500 & 4500 & 5 & 4 \\
\hline $\mathrm{Ac} / \mathrm{As}$ & 69 & 70 & 74 & 68 & - & - & 5400 & 4300 & 9 & 5 \\
\hline Ns & 93 & 93 & 99 & 98 & - & - & 6500 & 6600 & 24 & 19 \\
\hline $\mathrm{Cb}$ & 75 & 70 & 79 & 69 & 890 & 520 & 6000 & 4200 & 11 & 6 \\
\hline $\mathrm{Cu}$ & 53 & 55 & 55 & 53 & 1000 & 630 & 4300 & 3500 & 6 & 4 \\
\hline $\mathrm{Sc}$ & 72 & 75 & 80 & 77 & 890 & 630 & 4800 & 4000 & 11 & 7 \\
\hline St & 80 & 86 & 91 & 91 & 510 & 430 & 5300 & 5000 & 18 & 12 \\
\hline Fog & 61 & 72 & 100 & 100 & 0 & 0 & 4300 & 3200 & 12 & 9 \\
\hline Clear* & 18 & 28 & 0 & 0 & - & - & 3700 & 2700 & 4 & 3 \\
\hline \multicolumn{11}{|l|}{ Alone } \\
\hline $\mathrm{Ci}$ & 37 & 43 & 48 & 39 & - & - & 5400 & 4400 & 3 & 3 \\
\hline $\mathrm{Ac} / \mathrm{As}$ & 42 & 46 & 39 & 39 & - & - & 4600 & 3500 & 5 & 3 \\
\hline $\mathrm{Cb}$ & 57 & 49 & 54 & 45 & 990 & 550 & 4500 & 2800 & 6 & 3 \\
\hline $\mathrm{Cu}$ & 39 & 38 & 35 & 35 & 1020 & 640 & 3300 & 2500 & 5 & 3 \\
\hline $\mathrm{Sc}$ & 47 & 54 & 47 & 49 & 940 & 690 & 3500 & 2800 & 6 & 4 \\
\hline St & 42 & 56 & 46 & 50 & 590 & 570 & 3500 & 3000 & 7 & 4 \\
\hline
\end{tabular}

* From DJF, JJA 1986 only.

sometimes to classification of these clouds as midlevel clouds by ISCCP. These results are also affected by the treatment of all clouds as liquid water clouds in the C-series data; this produces overestimates of optical thicknesses for clouds that are actually composed of ice, which would be predominant in northern midlatitudes in DJF (Rossow et al. 1996). Another possible contributor to the land-ocean difference is that the cloud fields are more uniform over the ocean, whereas over land the satellite could be detecting different cloud types in other parts of the grid box and/or other times within the 3-h time bin of ISCCP.

There is little difference in the patterns between DJF and other seasons. In all seasons, for both land and ocean, $\mathrm{Cu}, \mathrm{Sc}$, and $\mathrm{St}$ are essentially indistinguishable from each other. The similarity of the three patterns indicates that satellite radiometric observations like ISCCP data cannot distinguish among these three low types when they occur alone (but we will see below that their patterns do differ when all cases are considered). This similarity of the patterns for $\mathrm{Cu}, \mathrm{Sc}$, and $\mathrm{St}$ also holds at low latitudes (not shown).

Over land the pattern for $\mathrm{Cb}$ (Fig. 6a) is distinguished somewhat from that of $\mathrm{Cu}, \mathrm{St}$, and $\mathrm{Sc}$ in that it is, as expected, more frequently found to be higher and thicker than the other three, but over the ocean the pattern for $\mathrm{Cb}$ is not significantly different from that of the other three low types. This is probably because there is less vertical development of $\mathrm{Cb}$ clouds over the ocean than over land as discussed above in section 3b. Hahn et al. (1996) show that the less vertically developed $C_{L}=3$ is the more commonly reported form of $\mathrm{Cb}$ over the ocean, whereas $C_{L}=9$ ( $\mathrm{Cb}$ with anvil) is more commonly reported over land. Correspondingly, $\mathrm{Cb}$ as de- fined by ISCCP is more common over land than over ocean (Machado and Rossow 1993), while $\mathrm{Cb}$ as reported by surface observers (Table 1) is more common over ocean than over land (Warren et al. 1986, 1988). These differences between SOBS and ISCCP in the $\mathrm{Cb}$ climatology are thus due to a difference in definitions: to report $\mathrm{Cb}$ the ground observer uses evidence of the cloud's shape and occurrence of precipitation, either at the station or at a distance, whereas ISCCP requires a thick cloud with a cold top.

All panels of Fig. 6, as well as most of the other figures, indicate that a significant number of pixels are classified as very high $(50-180 \mathrm{mb})$ and very thin $(\tau$ $<1.3)$. These are very thin cirrus detected from satellite by their low temperatures but not thick enough to be seen in reflected sunlight in the visible channel; some of these clouds are "subvisible" and will be missed by surface observers (Sassen and Cho 1992; Wylie et al. 1995). This feature is less evident in the Ns patterns, because it can exist only when the troposphere is otherwise free of clouds in some parts of the grid box. ISCCP actually underestimates the amount of these thin high clouds (Liao et al. 1995; Jin et al. 1996).

\section{b. Upper-level cloud types alone, and fog}

In section $3 \mathrm{~b}$ we noted that the average cloud tops in ISCCP-C1 for $\mathrm{Ci}$ and Ac were lower than expected. Figure $7 \mathrm{a}$ shows that this happens because cirrus over land is usually diagnosed as high and thin, as expected, but there is also some occurrence of low clouds. Over the ocean (Fig. 7b) there is a more substantial contribution of clouds diagnosed as low and moderately thin. These are probably boundary layer clouds in another 
LAND
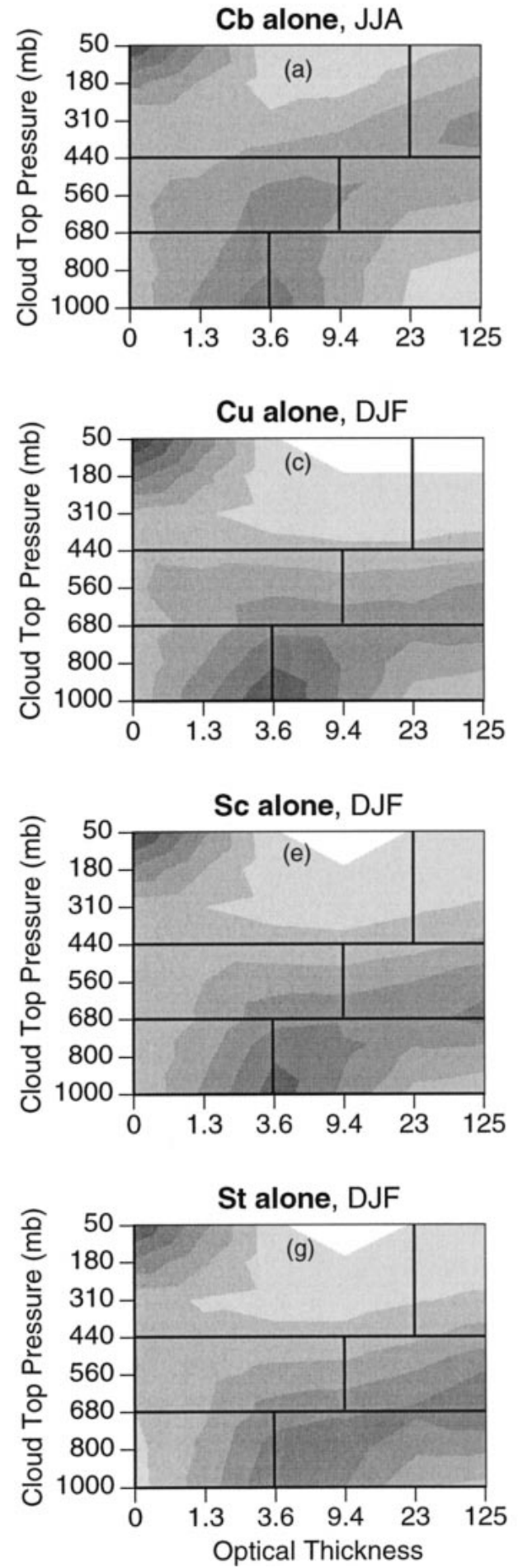

OCEAN

$\mathrm{Cb}$ alone, JJA

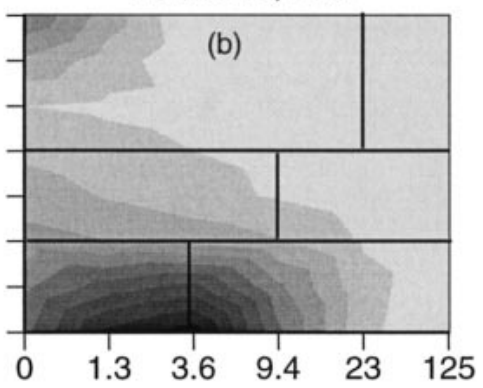

Cu alone, DJF

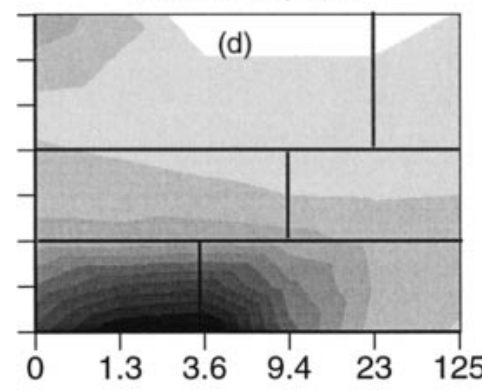

Sc alone, DJF

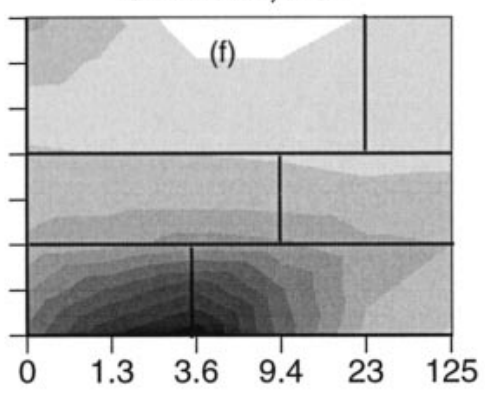

St alone, DJF

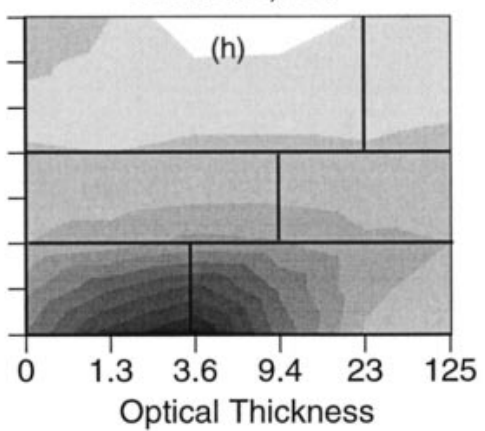

FIG. 6. Distributions of values of cloud-top pressure $p_{c}$ and optical thickness $\tau$ in $\mathrm{C} 1$ data for grid boxes of size $280 \mathrm{~km} \times 280 \mathrm{~km}$, in which the specified low cloud type was reported alone in surface observations, for the season DJF in the zone $30^{\circ}-45^{\circ} \mathrm{N}$. (For $\mathrm{Cb}$, results are shown for JJA instead of DJF.) The grayscale indicates the normalized amounts in units of "percent per $\tau-p_{c}$ bin" for the $35 \tau-p_{c}$ bins. 
LAND

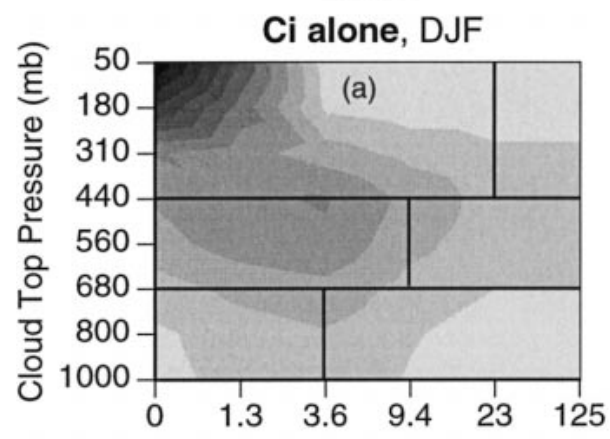

Ac alone, DJF
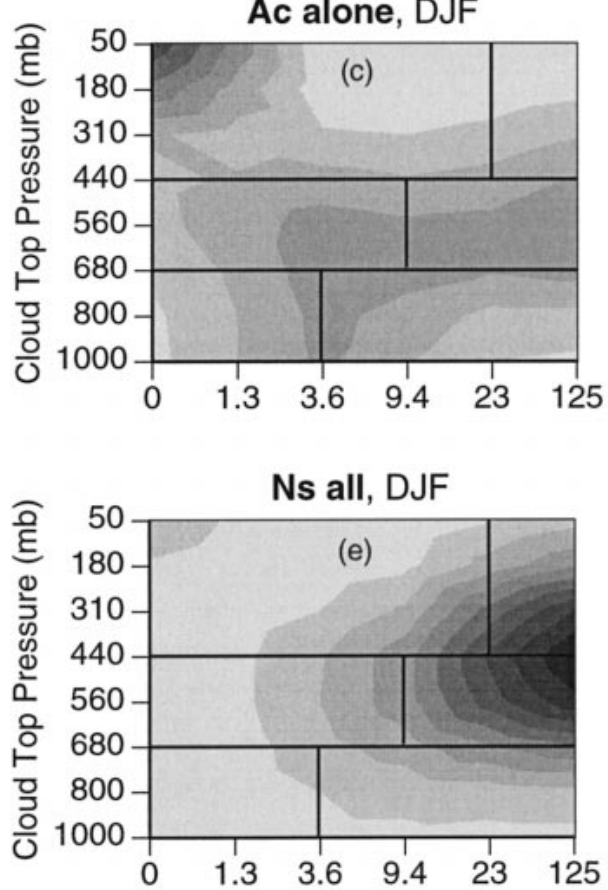

Fog all, DJF

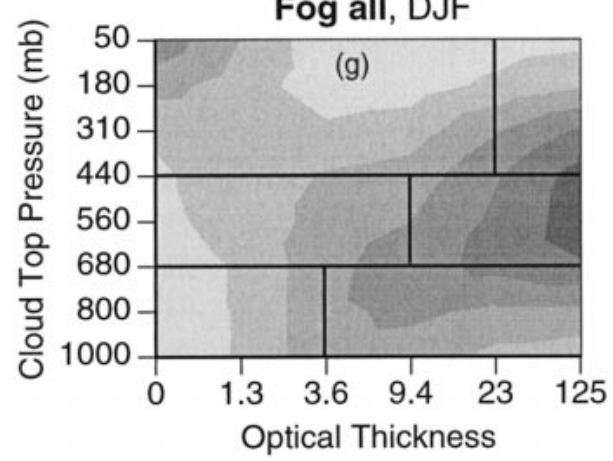

OCEAN

Ci alone, DJF

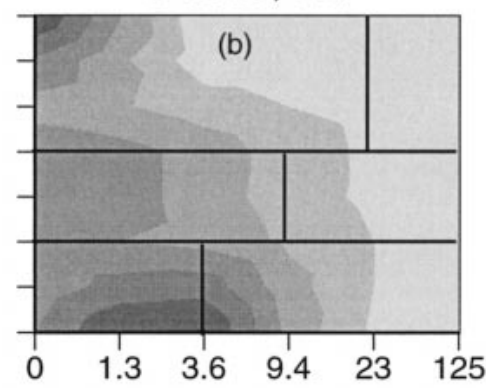

Ac alone, DJF

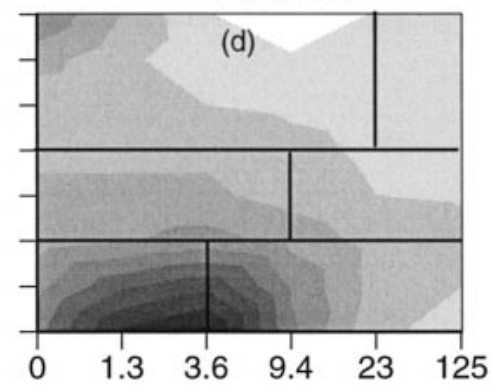

Ns all, DJF

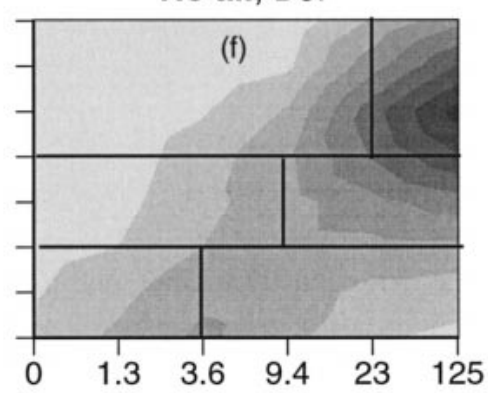

Fog all, DJF

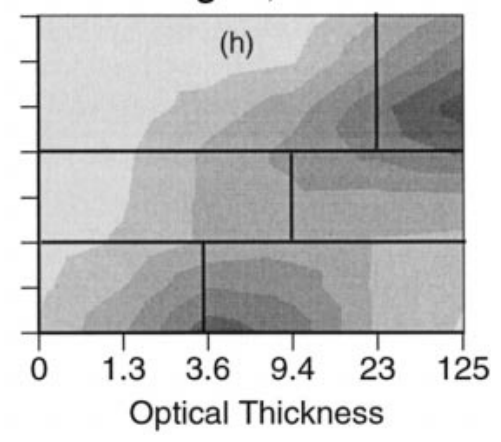

FIG. 7. Distributions of $\left(\tau, p_{c}\right)$ for surface reports of $\mathrm{Ci} / \mathrm{Cs} / \mathrm{Cc}$ ("Ci") and $\mathrm{Ac} / \mathrm{As}$ ("Ac") occurring alone, and the "all" cases for Ns and fog, for DJF in the zone $30^{\circ}-45^{\circ} \mathrm{N}$. The grayscale is defined in Fig. 6. 
LAND
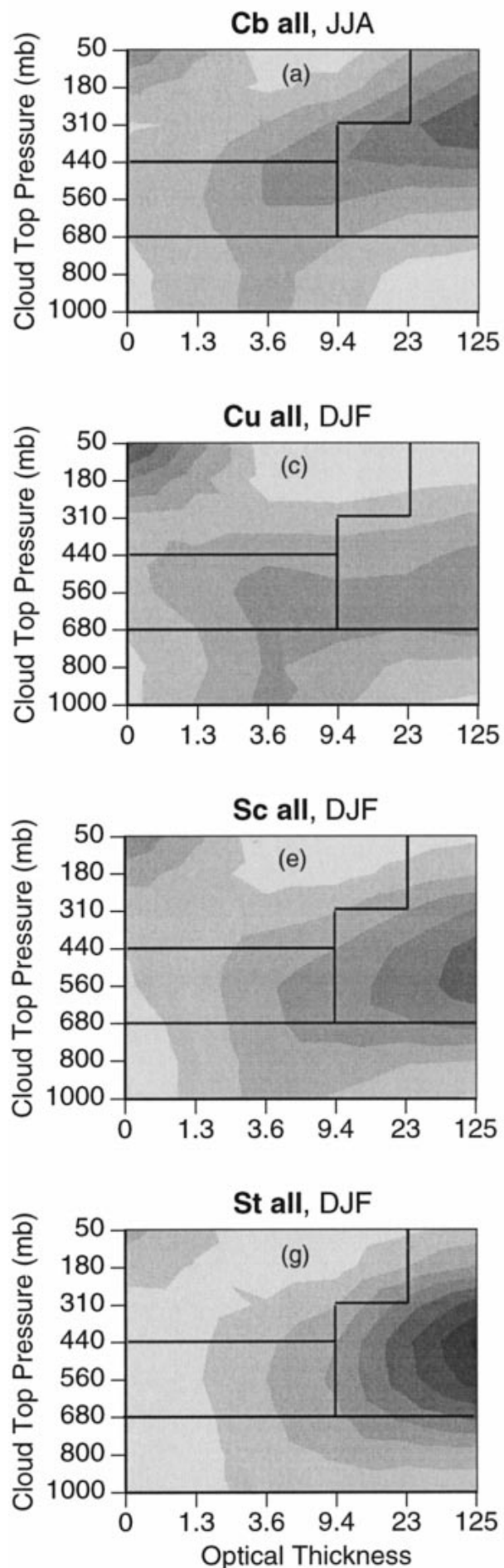

OCEAN

$\mathrm{Cb}$ all, JJA

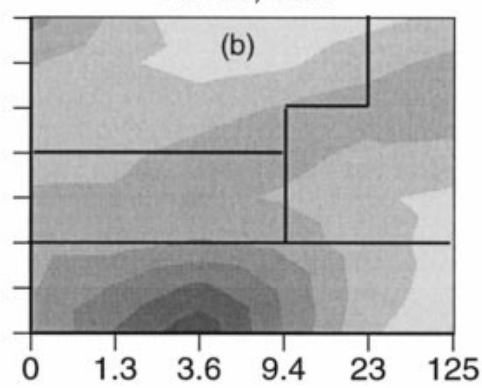

Cu all, DJF

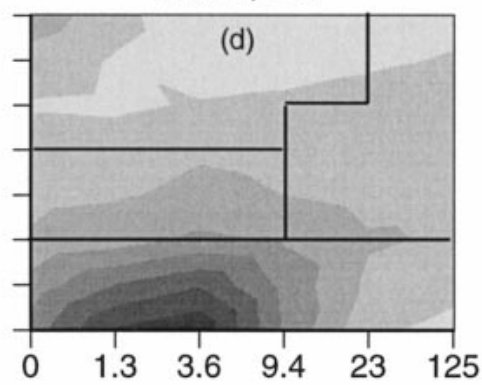

Sc all, DJF

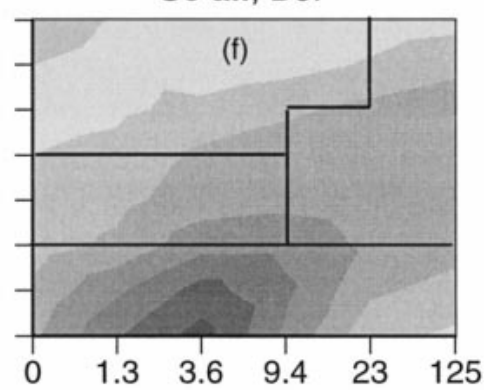

St all, DJF

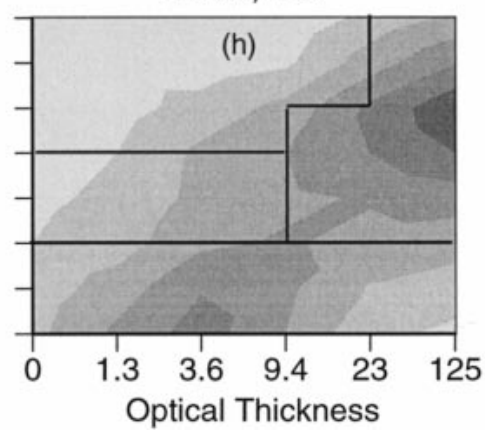

FIG. 8. Distributions of $\left(\tau, p_{c}\right)$ for surface reports of low clouds, irrespective of whether other clouds are also present (the "all" cases), for DJF in the zone $30^{\circ}-45^{\circ} \mathrm{N}$, except that JJA statistics are shown for $\mathrm{Cb}$ because $\mathrm{Cb}$ is more common in summer. The grayscale is defined in Fig. 6. 
LAND
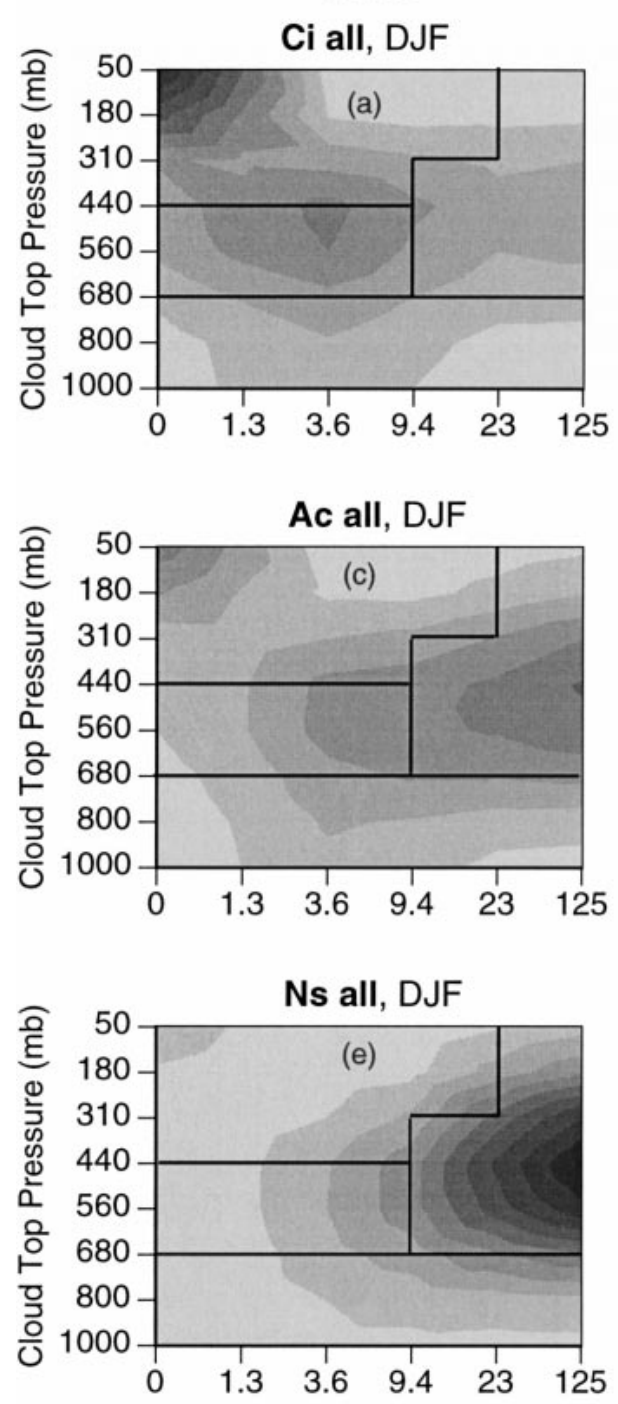

Fog all, DJF

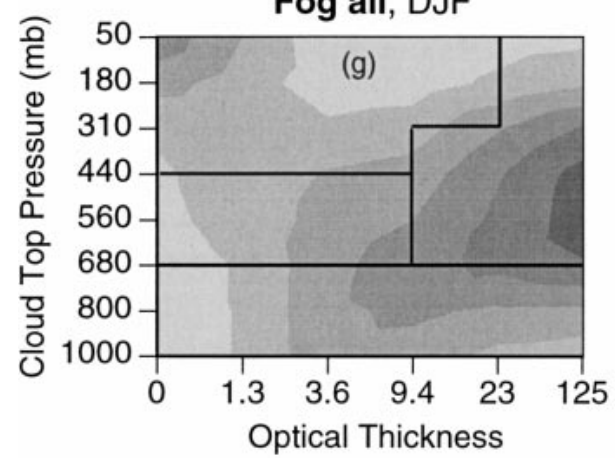

OCEAN

Ci all, DJF

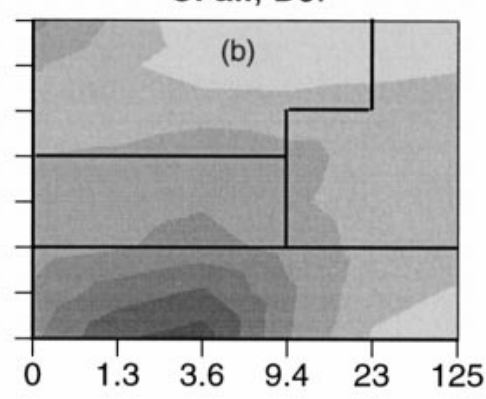

Ac all, DJF

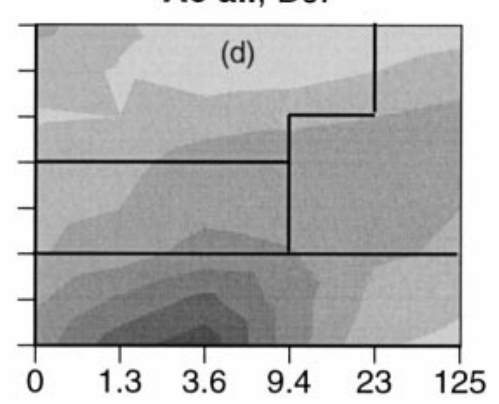

Ns all, DJF

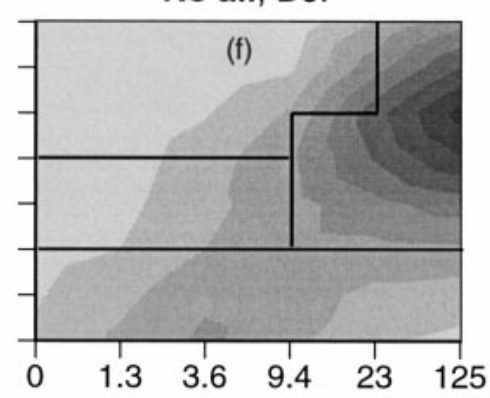

Fog all, DJF

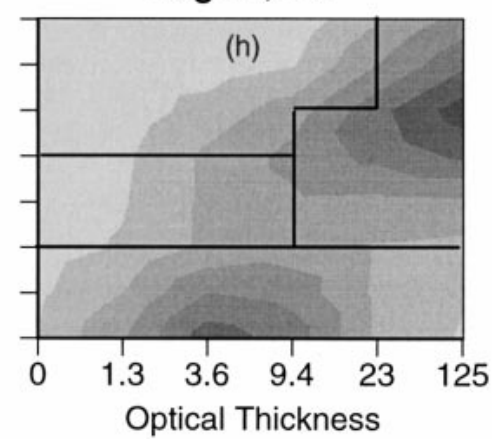

FIG. 9. Distributions of $\left(\tau, p_{c}\right)$ for surface reports of upper clouds, middle clouds, and fog, irrespective of whether other clouds are also present (the "all" cases), for DJF in the zone $30^{\circ}-$ $45^{\circ} \mathrm{N}$. The grayscale is defined in Fig. 6. 
part of the grid box not seen by the ship observer, since it is rare for $\mathrm{Ci}$ to occur alone over the ocean (Table 2; Fig. 2 of Warren et al. 1985).

The Ac/As alone (Figs. 7c,d) has a pattern that resembles $\mathrm{Cu}$ alone (Figs. 6c,d) but with somewhat higher cloud tops (Table 3). Over the ocean the peak frequency is in the boundary layer, probably for the same reason mentioned for $\mathrm{Ci}$. Over land the peak frequency is in the midlevel. The thick midlevel clouds detected over land could represent a contribution from thick As $\left(C_{M}\right.$ $=2$ ), which is similar to Ns but without concurrent precipitation (Table 1 ).

The pattern for $\mathrm{Ci} / \mathrm{Cs} / \mathrm{Cc}$ alone (Fig. 7a) and the pattern for Ac/As alone (Fig. 7b) both include high-level clouds of small optical thickness and midlevel clouds of medium optical thickness. This feature of the patterns is explained by the ground observer's difficulty in distinguishing $\mathrm{Cs}$ from As. The ground observer tends to call the thinner cloud $\mathrm{Cs}$ and the thicker cloud As. The satellite retrievals, which can obtain height more accurately than the ground observer, indicate that this assumption has some validity.

At $0^{\circ}-15^{\circ} \mathrm{N}$ (not shown) the ocean patterns for middle and high types are somewhat different than at midlatitudes, in that they are not dominated by low, moderately thick clouds as they are at $30^{\circ}-45^{\circ} \mathrm{N}$. This could mean that when Ac and $\mathrm{Ci}$ occur alone in the equatorial region they are more extensive in area than they are at midlatitudes and therefore effectively hide low clouds from the satellite's view.

Because nimbostratus and fog (sky obscured due to fog) cover the entire sky, the ground observer can never be sure that they are "alone." We therefore have no patterns for these types "alone," so they are shown in Fig. 7 for "all" occurrences. Nimbostratus displays a distinctive, strongly peaked signature of an optically thick cloud with a top in the mid- to upper troposphere, in all seasons and all zones over both land and ocean. It is sufficiently extensive in area that few low-level clouds are visible to the satellite, even over the ocean where low-level clouds contribute significantly to the patterns for all other cloud types.

The bottom panels of Fig. 7 show the cloud characteristics detected by ISCCP when the surface observer's sky is obscured by fog. There is often thick, extensive, mid- to upper-level cloud present (Ns or thick As), either above the fog or in another part of the grid box. Fog is diagnosed by ISCCP as a surface cloud (i.e., not hidden by overlying clouds) more often over ocean than over land, although some of this low cloud is likely to be $\mathrm{Cu}, \mathrm{Sc}$, or $\mathrm{St}$ in another part of the box. Over land, fog occurring alone, which could be seen from above, is most common at night and early morning, times that were excluded from this study as explained in section 2. Fog over the ocean (Fig. 7h) has a bimodal signature; it sometimes appears to be alone, as a cloud at the sea surface, but also appears often to coexist with Ns or As.

\section{c. Revised classification of cloud types in $\tau-p_{c}$ space}

We now compare the observed $\tau-p_{c}$ distributions of the cloud types with the assignment suggested in Fig. 1a. Table 3 shows that the average heights and optical depths of the three low cloud types $\mathrm{Cu}, \mathrm{Sc}$, St differ significantly from each other (especially for "all" the cases) as suggested by Rossow et al. (1991), but Fig. 6 shows that the distributions of those radiometrically derived properties are so broad that they cannot be used to distinguish individual examples of the three low cloud types. Therefore, for the revised classification scheme in Fig. 1b, we removed the boundary between cumulus and stratus to make a single low-cloud group (which also includes fog). We also see that the average properties of $\mathrm{Cb}$, Ns, and thick As vary systematically (Table 3 ), but that their signatures overlap (Figs. 6 and 7), so we removed the boundary between deep convective (Cb) and nimbostratus. The boundary between the $\mathrm{Cb} /$ $\mathrm{Ns} / \mathrm{As}$ group and the cirriform group was modified to better fit the extent of the distributions observed for Ns and $\mathrm{Cb}$. It is appropriate for $\mathrm{Ns}$ and thick As to be grouped together, because they are both coded $C_{M}=2$ and distinguished only by whether they are precipitating. In this study we did not distinguish thick Cs from the other cirriform clouds. The revised boundaries of Fig. 1b are incorporated into Figs. 8 and 9 (the "all" cases, discussed below). Figures $9 \mathrm{e}-\mathrm{h}$ can be compared directly with Figs. 7e-h to see the effect of the changed boundaries for the cases of Ns and fog.

\section{d. "All" occurrences of the cloud types}

It is much more common for the individual cloud types to occur together with other clouds than to occur alone (Table 2). Examples for the "all" cases (which include the "alone" cases as well as the co-occurrences) are given in Figs. 8 and 9 for the zone $30^{\circ}-45^{\circ} \mathrm{N}$ for DJF, except that JJA distributions are shown for $\mathrm{Cb}$.

Figures $8 \mathrm{c}-\mathrm{h}$ show $\tau-p_{c}$ distributions for all surface reports of the low cloud types $\mathrm{Cu}, \mathrm{Sc}$, and St. These low clouds commonly co-occur with middle and high clouds (Warren et al. 1985) and this is apparent in the distributions. Stratus (Figs. 8g,h) shows a strong tendency to co-occur with Ns or As, appearing as a very thick middle cloud. Over land this middle cloud dominates the satellite view, obscuring the signature of $\mathrm{St}$ itself (cf. Fig. 6g), although over the ocean some low cloud is still detected. This result is expected because of the different viewpoints of the two sets of observations (bottom up vs top down). Stratocumulus (Figs. $8 \mathrm{e}, \mathrm{f})$ is less likely than St to co-occur with Ns/As, particularly over ocean, and correspondingly shows a pattern less dominated by thick, midlevel clouds. The midlevel clouds are still prominent over land, but less so than with St. Of the low cloud types, $\mathrm{Cu}$ is the least likely to co-occur with Ns/As, and its pattern shows even less contribution from thick middle clouds but 
more from Ac and $\mathrm{Ci}$, particularly over land. Over the ocean low clouds dominate the pattern.

Thus we see that, although these three low types are difficult to distinguish from the satellite when they occur alone, the three types occur as part of different patterns of cloud property distributions when all cases of these types are considered.

Cumulonimbus over land (Fig. 8a) shows its expected signature as a high-topped, optically thick cloud, which was not exhibited by the alone cases. Oceanic $\mathrm{Cb}$ in JJA (Fig. 8b) also shows some contribution from high, thick cloud but still retains a peak frequency in the low, moderately thick region (cf. Fig. 6b).

Figure 9 shows the "all" cases of $\mathrm{Ci}$ and Ac/As, which exhibit slight increases in both optical thickness and height when compared with the "alone" cases in Fig. 7. In the case of Ac/As this may be attributed to overlying cirrus. In the case of cirrus it is probably due to the addition of underlying clouds, which have the effect of decreasing the inferred cloud-top temperature, because in the case of (thin) cirrus alone the brightness temperature would have a greater contribution from the surface, which is normally warmer than midlevel clouds. Warren et al. (1985), using only surface observations, showed that when $\mathrm{Ci}$ is present Ac/As is very frequently also present (two-thirds of the time over the ocean) and that there is a significant cooccurrence of $\mathrm{Ns}$ with $\mathrm{Ci}$ as well.

The low cloud peak that dominated the pattern in the Ac alone case over ocean (Fig. 7d) is weaker in the "all" case (Fig. 9d), probably due to a more extensive As or Ac that hides the lower clouds from the satellite's view, rather than to any actual reduction in the amount of low-level clouds. The Ac all case also shows a greater contribution from overlying cirrus, as is to be expected. Note also that for $\mathrm{Ci}$ and Ac, "all" means all cases in which $\mathrm{Ci}$ or Ac was observed from below; cases of $\mathrm{Ci}$ or Ac above a lower overcast are not observable from the ground and so do not contribute to Fig. 9. For example, cases of $\mathrm{Ci}$ above Ns are excluded from Figs. 9a,b; such cases would exhibit large optical depths.

Figure 9 also displays the distributions for Ns and fog, which were discussed in section $4 b$. Figures $9 e-h$ are identical to Figs. 7e-h except for the redefined boundaries as in Fig. 1b rather than Fig. 1a. Comparison of the two figures indicates that with the new boundaries nearly all Ns cases fall into the region of $\tau-p_{c}$ space designated as $\mathrm{Cb} / \mathrm{Ns} / \mathrm{As}$.

\section{Multiple simultaneous surface observations in the same grid box}

A source of ambiguity in our comparisons has been the possibility that a single observation by a surface observer somewhere in a $280-\mathrm{km}$ grid box may not be representative of the entire box at the time of observation. To examine that source of ambiguity we searched a portion of the surface dataset (January and July 1986)
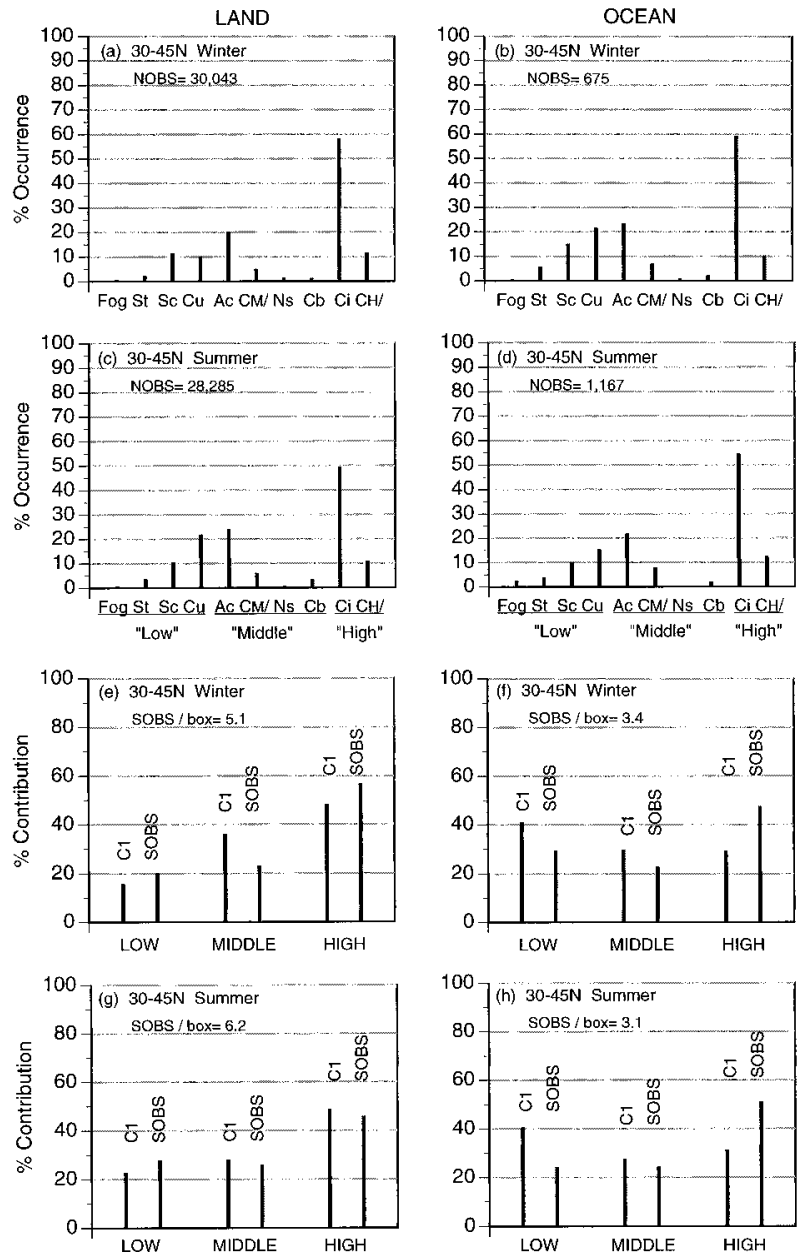

FIG. 10. Variability of cloud conditions within a $280-\mathrm{km}$ grid box, when multiple surface observations were made in the same box at the same time that one of these observations was a report of $\mathrm{Ci} / \mathrm{Cs} /$ Cc occurring alone. (a)-(d) Occurrence of indicated cloud types in multiple surface observations (SOBS) for winter and summer seasons, and land and ocean separately for the latitude zone $30^{\circ}-45^{\circ} \mathrm{N}$. The number of SOBS (NOBS) contributing to the analysis is given in each frame. The notation CM/ means the middle cloud level was not reported; $\mathrm{CH} /$ means the high cloud level was not reported (see Table 1). (e)-(h) Contributions from low, middle and high levels as reported by ISCCP-C1 (left vertical bar of each pair) and by SOBS (right bar), normalized to a total of $100 \%$ (see section 5 of the text for definitions of levels). The average number of simultaneous surface observations in a grid box is given in each frame. For C1 data, winter is DJF 1984-91 and summer is JJA 1983-90. For SOBS data, winter is Jan 1986 and summer is Jul 1986.

for times when multiple surface observations were made within one $280-\mathrm{km}$ grid box and at least one of those surface observations was a report of cirrus occurring alone (this selection was made to maximize the probability that all surface observers in the grid box would be able to see clouds, if present, throughout the depth of the troposphere). The frequency of occurrence of cloud types reported by the multiple surface observers was computed for these cases. These results are shown in Figs. $10 \mathrm{a}-\mathrm{d}$ for the zone $30^{\circ}-45^{\circ} \mathrm{N}$ for the winter and 
summer seasons (represented here by January and July 1986). The figure shows that $\mathrm{Ci}$ is reported in $50 \%-$ $60 \%$ of the simultaneous reports, that in another $10 \%$ of the reports the high level is not visible, and that the other most commonly reported types in this situation are $\mathrm{Ac}, \mathrm{Cu}$, and $\mathrm{Sc}$.

Surface statistics were then compared with ISCCP$\mathrm{C} 1$ cloud retrievals for cases of $\mathrm{Ci}$ reported alone (in the surface observation) for these two seasons in the same zone (Figs. 10e-h). For this comparison the $\mathrm{C} 1$ data (all of which had already been sorted into a " $\mathrm{Ci}$ alone" class) were grouped into three levels based on their cloud-top pressure: low (1000-680 mb), middle (680-440 mb), and high (440-50 mb). For comparison with ISCCP-C1, the surface reports for January and July 1986 (again, in which at least one of the reports was of $\mathrm{Ci}$ alone) were also grouped: fog, $\mathrm{St}, \mathrm{Sc}$, and $\mathrm{Cu}$ were considered to be in the low level; Ac, $C_{M}=/$, Ns, and $\mathrm{Cb}$ in the middle level; and $\mathrm{Ci}$ and $C_{H}=/$ in the high level. [We have seen that $\mathrm{Cb}$ sometimes appears to the satellite in any of the three levels and that Ns appears in the mid- or high levels. The choice to count $\mathrm{Cb}$ and Ns in the midlevel for this comparison is of little consequence because their occurrence is rare in this situation of $\mathrm{Ci}$ reported alone nearby. The choice to include $C_{M}=/$ and $C_{H}=/$ (Table 1) as indicating clouds at their respective levels is probably correct but again of little consequence because of the infrequent occurrence of such reports under the given condition.]

The values plotted in Figs. 10e-h are normalized to $100 \%$ so that frequencies for each level represent the fraction of all clouds detected that are contributed by the particular level. If the entire grid box were uniformly in agreement with the report of $\mathrm{Ci}$ alone, the high values would all read $100 \%$. In fact, the high values among the surface observations (right vertical bar of each pair) are $46 \%$ (land) and $57 \%$ (ocean), and among the satellite observations (left bar) are $49 \%$ (land) and 29\% (ocean). Notably, the distribution of other cloud types seen elsewhere in the grid box by the multiple surface observers is in approximate agreement with the averages of the ISCCP reports. This supports the suggestion made earlier that the low clouds detected by satellite in the $\mathrm{Ci}$ alone cases, as well as for the clear and Ac alone cases, are a consequence of the satellite's detecting other clouds outside the field of view of the surface observer. This suggests that a comparison of each surface observation with the corresponding simultaneous individual pixel might produce better agreement than we have found by comparing with an entire grid box. However, such a comparison would suffer from a reversed mismatch of scales, where the satellite field of view would be much smaller than that of the surface observer. Furthermore, the surface observer's field of view varies with cloud height: it includes a few pixels at the low cloud level, several pixels at the middle level, and many pixels at the high level. An alternative might be to limit comparisons of the sort shown in Figs. 2-9 to cases where there were multiple simultaneous SOBS in a single ISCCP grid box, which would severely limit the geographical coverage possible. A better alternative might be to aggregate ISCCP pixels for an area smaller than the grid box, perhaps $50 \mathrm{~km}$ on a side instead of $280 \mathrm{~km}$.

\section{Summary and conclusions}

From this direct comparison of ISCCP cloud retrievals with individual surface observations of particular cloud types, we were able to confirm some previously observed characteristics of these two different methods of cloud observation and to provide new insights into the relationships between the two. We have drawn the following conclusions.

1) Average total cloud amount, contingent on the occurrence of each particular cloud type, shows general agreement between ISCCP and SOBS in low latitudes and midlatitudes. There is a tendency for SOBS TCA to exceed C1 TCA over land and the reverse over the ocean. Agreement is poor in the polar regions.

2) Cloud-top heights retrieved by ISCCP and averaged over a $280-\mathrm{km}$ grid box in which a surface observer reported Ac/As or cirrus clouds alone are lower than might be expected for these midlevel and upper-level clouds. The $\tau-p_{c}$ distributions suggest that a major reason for this is the satellite's detection of other (lower) clouds in other parts of the box outside the field of view of the surface observer. (Additional reasons, for cirrus, are that the cloud may not be opaque in the infrared and that the surface observer may mistake thin As for Cs.) The highest average cloud tops are found when nimbostratus is reported by the surface observer, averaging $7 \mathrm{~km}$ and reaching $9 \mathrm{~km}$ in the ITCZ.

3) The greatest average optical thickness is also associated with Ns, with $\tau \approx 20$. All other cloud types are diagnosed with average optical thickness $\tau \approx 4$ when alone, but the optical thicknesses of multilevel cloud scenes vary as expected for the cloud assemblages typical of each low type.

4) When occurring alone, individual scenes of St, Sc, and $\mathrm{Cu}$ cannot be distinguished by ISCCP, since their $\tau-p_{c}$ distributions overlap significantly. Thus these three types must be considered simply as "low clouds" in the $\tau-p_{c}$ diagram. The lower-right corner of the $\tau-p_{c}$ diagram, which might be expected to represent stratus, is sparsely populated; ISCCP rarely detects optically thick clouds with low tops.

5) The $\tau-p_{c}$ distributions for Cb and Ns (and thick As) overlap to such an extent that these types cannot be distinguished by ISCCP.

6) Although several different defined cloud types exhibit very similar $\tau-p_{c}$ patterns when alone, their $\tau-p_{c}$ patterns are distinguishable when all occur- 
rences of the cloud types are considered. For example, when stratus is present in the low level, Ns is very likely to be present in the middle level; Ns is progressively less likely to cooccur with $\mathrm{Sc}$, fog, and $\mathrm{Cu}$. Also, $\mathrm{Cb}$ and $\mathrm{Ns}$ differ in that low clouds are far more often detected from above with $\mathrm{Cb}$ than with Ns. Thus, the cloud types defined and reported by surface observers do distinguish atmospheric conditions that can be verified by satellite. The studies of Lau and Crane $(1995,1997)$ show a similar result in a different way: that there is a characteristic spatial distribution of cloud properties associated with specific meteorological situations. Exploration of the relations of these cloud property distribution patterns to meteorological conditions warrants more study using these and other meteorological datasets.

7) It is important to consider differences in field of view when comparing surface cloud observations with simultaneous satellite cloud retrievals.

The goal of this study was to relate surface-defined cloud types to satellite-inferred heights and thicknesses. We have seen that comparison of individual scenes suffers from scale differences and that some surface-defined cloud types are not distinguished by ISCCP. Thus we presented Fig. 1b to delineate a practical correspondence between the two types of data. In Fig. 1b the number of distinguishable cloud types is reduced to four: low clouds $(\mathrm{Cu}, \mathrm{Sc}, \mathrm{St}$, fog), thin middle clouds [Ac and thin As $\left(C_{M}=1\right)$, cirriform clouds $(\mathrm{Ci}, \mathrm{Cs}$, $\mathrm{Cc})$, and the high-topped, thick clouds $[\mathrm{Cb}, \mathrm{Ns}$, and thick As $\left.\left(C_{M}=2\right)\right]$. It seems likely that $\mathrm{Cb}$ in the highthick group is predominantly $C_{L}=9$, and that $C_{L}=3$ would be better placed with $\mathrm{Cu}$ in the low group. Using such definitions it might be possible to obtain climatologies of cloud types in which the two datasets would correspond well.

However, since surface-defined cloud types do not correspond uniquely to defined regions of $\tau-p_{c}$ space, for many purposes it may be best not to use the traditional cloud names for ISCCP $\tau-p_{c}$ domains, instead referring to them by names such as "high-thick" and "low-thin."

Acknowledgments. The construction and preliminary statistical analysis of the merged dataset of surface observations and ISCCP cloud retrievals were done by Alison Walker, who also assisted us in working with this dataset. Stephen Klein and an anonymous reviewer provided helpful suggestions to improve the manuscript. This work was supported in part by a joint NSF-NOAA Grant ATM-95-10170.

\section{REFERENCES}

Chambers, W. L., B. A. Wielicki, and K. F. Evans, 1997: Accuracy of the independent-pixel approximation for satellite estimates of oceanic boundary layer cloud optical depth. J. Geophys. Res., 102, 1779-1794.
Chen, T., W. B. Rossow, and Y.-C. Zhang, 2000: Radiative effects of cloud-type variations. J. Climate, 13, 264-286.

Hahn, C. J., and S. G. Warren, 1999: Extended edited synoptic cloud reports from ships and land stations over the globe, 1952-1996. Numerical Data Package NDP-026C, 71 pp. [Available from Carbon Dioxide Information Analysis Center, Oak Ridge National Laboratory, Oak Ridge, TN 37831-6335.]

_ - _ - and J. London, 1995: The effect of moonlight on observation of cloud cover at night, and application to cloud climatology. J. Climate, 8, 1429-1446.

,-- , and — 1996 : Edited synoptic cloud reports from ships and land stations over the globe, 1982-1991. Numerical Data Package NDP-026B, 47 pp. [Available from Carbon Dioxide Information Analysis Center, Oak Ridge National Laboratory, Oak Ridge, TN 37831-6335.]

Han, Q., W. B. Rossow, and A. A. Lacis, 1994: Near-global survey of effective cloud droplet radii in liquid water clouds using ISCCP data. J. Climate, 7, 465-497.

Houze, R. A., Jr., 1993: Cloud Dynamics. Academic Press, 573 pp. , 1997: Stratiform precipitation in regions of convection: A meteorological paradox? Bull. Amer. Meteor. Soc., 78, 2179-2195.

Jin, Y., and W. B. Rossow, 1997: Detection of cirrus overlapping low-level clouds. J. Geophys. Res., 102, 1727-1737.

,-- , and D. P. Wylie, 1996: Comparison of the climatologies of high-level clouds from HIRS and ISCCP. J. Climate, 9, 28502879.

Johnson, R. H., T. M. Rickenbach, S. A. Rutledge, P. E. Ciesielski, and W. H. Schubert, 1999: Trimodal characteristics of tropical convection. J. Climate, 12, 2397-2418.

Lau, N.-C., and M. W. Crane, 1995: A satellite view of the synopticscale organization of cloud properties in midlatitude and tropical circulation systems. Mon. Wea. Rev., 123, 1984-2006.

$\longrightarrow$, and — 1997: Comparing satellite and surface observations of cloud patterns in synoptic-scale circulation systems. Mon. Wea. Rev., 125, 3172-3189.

Liao, X., W. B. Rossow, and D. Rind, 1995: Comparison between SAGE II and ISCCP high-level clouds. Part I: Global and zonal mean cloud amounts. J. Geophys. Res., 100, 1121-1135.

Machado, L. A. T., and W. B. Rossow, 1993: Structural characteristics and radiative properties of tropical cloud clusters. Mon. Wea. Rev., 121, 3234-3260.

Minnis, P., K.-N. Liou, and Y. Takano, 1993: Inference of cirrus cloud properties using satellite-observed visible and infrared radiances. Part I: Parameterization of radiance fields. J. Atmos. Sci., 50, 1279-1304.

Pincus, R., S. A. McFarlane, and S. A. Klein, 1999: Albedo bias and the horizontal variability of clouds in subtropical marine boundary layers: Observations from ships and satellites. J. Geophys. Res., 104, 6183-6191.

Ramage, C. S., 1971: Monsoon Meteorology. Academic Press, 296 pp.

Rossow, W. B., and R. A. Schiffer, 1991: ISCCP cloud data products. Bull. Amer. Meteor. Soc., 72, 2-20.

- and — 1999: Advances in understanding clouds from ISCCP. Bull. Amer. Meteor. Soc., 80, 2261-2257.

, L. C. Garder, P. J. Lu, and A. W. Walker, 1991: International Satellite Cloud Climatology Project (ISCCP), documentation of cloud data. WMO/TD-266 (revised), World Climate Research Programme (ICSU and WMO), Geneva, Switzerland, 76 pp. plus 3 appendixes.

- A. W. Walker, and L. C. Garder, 1993: Comparison of ISCCP and other cloud amounts. J. Climate, 6, 2394-2418.

,-- D. E. Beuschel, and M. D. Roiter, 1996: International Satellite Cloud Climatology Project (ISCCP) documentation of new cloud datasets. WMO/TD-737, World Climate Research Programme (ICSU and WMO), Geneva, Switzerland, $115 \mathrm{pp}$.

Sassen, K., and B. S. Cho, 1992: Subvisual-thin cirrus lidar dataset for satellite verification and climatological research. J. Appl. Meteor., 31, 1275-1285. 
Schweiger, A. J., and J. R. Key, 1992: Arctic cloudiness: Comparison of ISCCP-C2 and Nimbus-7 satellite-derived cloud products with a surface-based cloud climatology. J. Climate, 5, 1514-1527.

Twohy, C. H., A. D. Clarke, S. G. Warren, L. F. Radke, and R. J. Charlson, 1989: Light-absorbing material extracted from cloud droplets and its effect on cloud albedo. J. Geophys. Res., 94, 8623-8631.

Wang, J., W. B. Rossow, T. Uttal, and M. Rozendaal, 1999: Variability of cloud vertical structure during ASTEX observed from a combination of rawinsonde, radar, ceilometer, and satellite. Mon. Wea. Rev., 127, 2484-2502.

- - - and Y. Zhang, 2000: Cloud vertical structure and its variations from a $20-y r$ global rawinsonde dataset. J. Climate 13, 3041-3056.

Warren, S. G., C. J. Hahn, and J. London, 1985: Simultaneous occurrence of different cloud types. J. Climate Appl. Meteor., 24, 658-667.

, R. M. Chervin, and R. L. Jenne, 1986: Globa distribution of total cloud cover and cloud type amounts over land. NCAR Tech. Note TN-273 + STR, Boulder, CO, 29 pp. and 200 maps.

,,,,---- and,- 1988 : Global distribution of total cloud cover and cloud type amounts over the ocean. NCAR Tech. Note TN-317 + STR, Boulder, CO, 42 pp. and 170 maps.

Wielicki, B. A., and L. Parker, 1992: On the determination of cloud cover from satellite sensors: The effect of sensor spatial resolution. J. Geophys. Res., 97, 12 799-12 823.

WMO, 1974: Manual on Codes. Vol. 1. WMO Publ. 306, World Meteorological Organization, $348 \mathrm{pp}$.

— 1975: International Cloud Atlas. Vol. 1. World Meteorological Organization, $155 \mathrm{pp}$.

, 1987: International Cloud Atlas. Vol. 2. World Meteorological Organization, $212 \mathrm{pp}$.

Woodruff, S. D., R. J. Slutz, R. L. Jenne, and P. M. Steurer, 1987: A Comprehensive Ocean-Atmosphere Data Set. Bull. Amer. Meteor. Soc., 68, 1239-1250.

Wylie, D., P. Piironen, W. Wolf, and E. Eloranta, 1995: Understanding satellite cirrus cloud climatologies with calibrated lidar optical depths. J. Atmos. Sci., 52, 4327-4343. 